


\section{The Role of Small Missions in Planetary and Lunar Exploration}

Committee on Planetary and Lunar Exploration

Space Studies Board

Commission on Physical Sciences, Mathematics, and Applications

National Research Council

Washington, D.C. 1995 
NOTICE: The project that is the subject of this report was approved by the Governing Board of the National Research Council, whose members are drawn from the councils of the National Academy of Sciences, the National Academy of Engineering, and the Institute of Medicine. The members of the committee responsible for the report were chosen for their special competences and with regard for appropriate balance.

This report has been reviewed by a group other than the authors according to procedures approved by a Repor Review Committee consisting of members of the National Academy of Sciences, the National Academy of Engineering, and the Institute of Medicine.

The National Academy of Sciences is a private, nonprofit, self-perpetuating society of distinguished scholars engaged in scientific and engineering research, dedicated to the furtherance of science and technology and to their use for the general welfare. Upon the authority of the charter granted to it by the Congress in 1863, the Academy has a mandate that requires it to advise the federal government on scientific and technical matters. Dr. Bruce M. Alberts is president of the National Academy of Sciences.

The National Academy of Engineering was established in 1964, under the charter of the National Academy of Sciences, as a parallel organization of outstanding engineers. It is autonomous in its administration and in the selection of its members, sharing with the National Academy of Sciences the responsibility for advising the federal government. The National Academy of Engineering also sponsors engineering programs aimed at meeting national needs, encourages education and research, and recognizes the superior achievements of engineers. Dr. Harold Liebowitz is president of the National Academy of Engineering.

The Institute of Medicine was established in 1970 by the National Academy of Sciences to secure the services of eminent members of appropriate professions in the examination of policy matters pertaining to the health of the public. The Institute acts under the responsibility given to the National Academy of Sciences by its congressional charter to be an adviser to the federal government and, upon its own initiative, to identify issues of medical care, research, and education. Dr. Kenneth I. Shine is president of the Institute of Medicine.

The National Research Council was organized by the National Academy of Sciences in 1916 to associate the broad community of science and technology with the Academy's purposes of furthering knowledge and advising the federal government. Functioning in accordance with general policies determined by the Academy, the Council has become the principal operating agency of both the National Academy of Sciences and the National Academy of Engineering in providing services to the government, the public, and the scientific and engineering communities. The Council is administered jointly by both Academies and the Institute of Medicine. Dr. Bruce M. Alberts and Dr. Harold Liebowitz are chairman and vice chairman, respectively, of the National Research Council.

Support for this project was provided by Contract NASW 4627 between the National Academy of Sciences and the National Aeronautics and Space Administration.

Cover: Diagram of the Near-Earth Asteroid Rendezvous spacecraft.

Copies of this report are available from

Space Studies Board

National Research Council

2101 Constitution Avenue, N.W

Washington, D.C. 20418

Copyright 1995 by the National Academy of Sciences. All rights reserved. Printed in the United States of America 


\section{COMMITTEE ON PLANETARY AND LUNAR EXPLORATION}

JOSEPH A. BURNS, ${ }^{*}$ Cornell University, Chair

RONALD GREELEY, Arizona State University, Continuing Chair

JAMES ARNOLD, University of California, San Diego

FRANCES BAGENAL, University of Colorado

GEOFFREY A. BRIGGS, ${ }^{*}$ NASA Ames Research Center

MICHAEL H. CARR, "U.S. Geological Survey

PHILIP R. CHRISTENSEN, Arizona State University

RUSSELL DOOLITTLE, University of California, San Diego

JAMES L. ELLIOT, ${ }^{*}$ Massachusetts Institute of Technology

JOHN F. KERRIDGE, ${ }^{* *}$ University of California, San Diego

BARRY H. MAUK, * Applied Physics Laboratory

WILLIAM B. McKINNON, " Washington University

EUGENE SHOEMAKER, U.S. Geological Survey

DARRELL F. STROBEL, Johns Hopkins University

ALAN F. TOKUNAGA, University of Hawaii

GEORGE W. WETHERILL, ${ }^{* *}$ Carnegie Institution of Washington

ROGER YELLE, University of Arizona

MARIA T. ZUBER, Johns Hopkins University

Staff

DAVID H. SMITH, Executive Secretary

ALTORIA B. ROSS, Senior Program Assistant

ERIN C. HATCH, Research Assistant

\footnotetext{
${ }^{*}$ Term ended in 1995.
}

**Term ended in 1994. 


\section{SPACE STUDIES BOARD}

CLAUDE R. CANIZARES, Massachusetts Institute of Technology, Chair JOHN A. ARMSTRONG, IBM Corporation (retired)

LAWRENCE BOGORAD, Harvard University

JOSEPH A. BURNS, ${ }^{*}$ Cornell University

JOHN J. DONEGAN, U.S. Navy (retired)

ANTHONY W. ENGLAND, University of Michigan

DANIEL J. FINK, D.J. Fink Associates, Inc.

MARTIN E. GLICKSMAN, Rensselaer Polytechnic Institute

RONALD GREELEY, Arizona State University

BILL GREEN, former member, U.S. House of Representatives

HAROLD J. GUY, " University of California, San Diego

NOEL W. HINNERS, Lockheed Martin Astronautics

JANET G. LUHMANN, University of California, Berkeley

JOHN H. McELROY, University of Texas, Arlington

ROBERTA BALSTAD MILLER, Consortium for International

Earth Sciences Information Network

BERRIEN MOORE III, University of New Hampshire

MARY JANE OSBORN, University of Connecticut Health Center

SIMON OSTRACH, Case Western Reserve University

CARLÉ M. PIETERS, Brown University

JUDITH PIPHER, ${ }^{*}$ University of Rochester

MARCIA J. RIEKE, University of Arizona

ROLAND SCHMITT, Clifton Park, New York

JOHN A. SIMPSON, University of Chicago

ARTHUR B.C. WALKER, JR.," Stanford University

MARC S. ALLEN, Director

${ }^{*}$ Former member. 


\section{COMMISSION ON PHYSICAL SCIENCES, MATHEMATICS, AND APPLICATIONS}

ROBERT J. HERMANN, United Technologies Corporation, Chair STEPHEN L. ADLER, Institute for Advanced Study PETER M. BANKS, Environmental Research Institute of Michigan SYLVIA T. CEYER, Massachusetts Institute of Technology L. LOUIS HEGEDUS, W.R. Grace and Co. JOHN E. HOPCROFT, Cornell University RHONDA J. HUGHES, Bryn Mawr College SHIRLEY A. JACKSON, U.S. Nuclear Regulatory Commission KENNETH I. KELLERMANN, National Radio Astronomy Observatory KEN KENNEDY, Rice University HANS MARK, University of Texas, Austin THOMAS A. PRINCE, California Institute of Technology JEROME SACKS, National Institute for Statistical Sciences L.E. SCRIVEN, University of Minnesota LEON T. SILVER, California Institute of Technology CHARLES P. SLICHTER, University of Illinois at Urbana-Champaign ALVIN W. TRIVELPIECE, Oak Ridge National Laboratory SHMUEL WINOGRAD, IBM T.J. Watson Research Center CHARLES A. ZRAKET, The MITRE Corporation (retired)

NORMAN METZGER, Executive Director 



\section{Preface}

The Committee on Planetary and Lunar Exploration advises the Space Studies Board on the entire range of planetary science topics; these include laboratory analytical and computational investigations, ground-based observations, and space missions. The disciplinary scope of its advice comprises geophysics, the atmospheric sciences, exobiology, particles and fields, planetary astronomy, and the search for planets around other stars.

Planetary missions of relatively low cost $(<\$ 150$ million [FY 1992 dollars] excluding launch and mission operations), having both limited development schedules and measurement objectives, have been proposed as an effective means of achieving planetary science goals. Solar system missions of this size include Clementine (a Department of Defense/NASA technology demonstration mission that in early 1994 made extensive measurements of the Moon but was aborted before a planned flyby of asteroid 1620 Geographos) and Near-Earth Asteroid Rendezvous (NEAR), approved for launch in early 1996; Mars Pathfinder (a technology demonstration mission to land a payload on Mars), being developed for a late 1996 launch, is of similar size but is somewhat different in character. According to NASA's plans, the last two missions, which received new starts in the FY 1994 budget, would be the first in a continuing program, called "Discovery." This document calls missions of this scale "small missions." Even though its components are of a comparable size, Mars Surveyor-a series of focused missions, including landers and orbiters-is not addressed in depth in this report because at least the first few flights, while low-cost, will be carried out much like previous NASA missions (i.e., will not be led by a principal investigator [PI]).

Given that the proposed mode of operation of small missions is different from that previously employed by NASA's Solar System Exploration Division, the Space Studies Board charged its Committee on Planetary and Lunar Exploration (COMPLEX) to address a number of issues associated with small missions. Prime among these issues was to examine the degree to which small missions can achieve priority objectives in the lunar and planetary sciences.

The study began with a meeting in Washington, D.C., in December 1993. Invited presenters briefed COMPLEX on the status of NEAR and Clementine as well as on lessons learned from NASA's Mars Observer and the Small Explorer program. In addition, the committee heard a series of personal views on the Discovery program by representatives from academia and the aerospace industry. The meeting concluded with a tour of the Clementine Control Center ("Batcave") in Alexandria, Virginia. The committee had previously been briefed on Mars Pathfinder during a visit to NASA's Jet Propulsion Laboratory in January 1993.

Work on the study continued in April 1994 at NASA's Ames Research Center in Moffett Field, California. COMPLEX heard a series of presentations from the PIs of a selection of candidate Discovery missions, each 
exhibiting a different managerial relationship between the PI's team, its industrial partner, and the associated NASA center. The committee's goal was not to assess the scientific potential or programmatic risk of any of these particular missions, but rather to focus on management issues. The meeting concluded with a round-table discussion of Discovery-related issues between the committee, PIs, and guests from NASA-Ames, local industry, and academia. As part of the outreach activities for this study, COMPLEX's chair made a public presentation to the space science community at NASA-Ames on the committee's recent studies.

The study continued at a summer workshop at the National Research Council's Beckman Center in Irvine, California, in May-June 1994. Part of this meeting was devoted to updates on the status of Mars Surveyor and Clementine, and plans devised by NASA's Outer Planets Science Working Group on small missions to the outer solar system. Work on the report was finished in the spring of 1995 following revisions arising from comments by the Space Studies Board and external reviewers.

Joseph A. Burns, Chair

Committee on Planetary and Lunar Exploration 


\section{Contents}

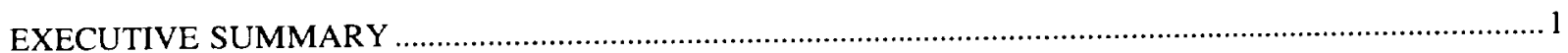

1 BACKGROUND AND CURRENT ENVIRONMENT …..............................................................

Planetary Explorer, 5

Planetary Observer, 7

Lunar Scout, 8

Clementine, 9

Discovery and Mars Surveyor, 9

References, 10

2 THE SMALL-MISSION CONCEPT

11

Explorers in Astrophysics, Space Physics, and Earth Sciences, 11

Small Missions in Planetary Exploration, 11

Relationship to Integrated Strategy, 12

The Need for a Balanced Program in Planetary and Lunar Exploration, 14

Attributes of an Effective Small-Missions Program for Planetary Exploration, 14

References, 16

3 TECHNOLOGICAL AND PROGRAMMATIC ASPECTS

Cost of Capable Small Missions, 17

The Need to Establish a Program, 17

Risk Philosophy, 18

Infrastructure, 19

Supporting Technology, 19

Subsidiary Goals, 20

Technology, 20

Education, 21

International Cooperation, 21

Program Issues, 22

Mission Operations, 22

Data Analysis and Archiving, 22

References, 23 
4 MANAGEMENT STRUCTURE AND PROCEDURES

Selection Criteria and Procedures, 24

Management Practices: Approach, Cost Control, and Roles, 25

Review and Oversight, 25

Descoping and/or Cancellation, 26

References, 26

5 RECOMMENDATIONS

Reference, 28 


\section{Executive Summary}

The last 30 years have seen remarkable progress in our understanding of the solar system and its diverse constituents. But this period has also seen an upheaval in the political and economic circumstances that have been among the prime drivers of planetary and lunar exploration. The motives that led the United States, the former Soviet Union, and, to a lesser extent, various European nations and Japan to explore the solar system during the past three decades were political as well as scientific. Now, with the end of the Cold War, the political motive has virtually disappeared. With such strong roots in the former East-West confrontation, the space program in general and planetary exploration in particular have become vulnerable to changing national priorities. Some observers question the utility of a space program as an instrument of national policy, and others point to the nation's altered economic fortunes and ask if space exploration is a luxury we can no longer afford.

Against this backdrop, the past successes of the planetary exploration program are, paradoxically, endangering its future vitality. Telescopic observations combined with the Apollo lunar landings and a string of highly successful robotic missions, including Vikings, Magellan, and the Voyagers, have given us a first-order understanding of all the planets and major satellites in the solar system from Sun-scorched Mercury to frigid Neptune; even Pluto's gross characteristics are known from ground-based and Earth-orbital measurements. Thus we have finished the preliminary reconnaissance of the major bodies in the solar system and have entered an era of intensive study of the physical phenomena that shape our planetary neighbors. Increased knowledge and comprehension lead us to pose more fundamental questions requiring increasingly sophisticated and expensive investigations to answer. Thus-quite naturally-the small, simple, and inexpensive spacecraft sufficient 20 to 30 years ago to record basic data about the planets have given way to multibillion-dollar robots capable of performing multidisciplinary investigations in the farthest reaches of the solar system.

But the increased scale and scope of planetary missions have a cost other than that measured in dollars. With a planetary program composed only of a few large missions, each spaceflight becomes precious. This is especially true in an environment of declining status and budgets for space exploration, where the failure of any given mission is no longer tolerable. A result is engineering conservatism, with engineers forced to seek the "perfect" design. At the same time, in a program of few spaceflights, scientists-fearing that no other missions will fly soon-will attempt to take the maximum advantage of available opportunities and potential gains from synergistic measurements, something that could, uncharitably, be interpreted as "trying to cram as much aboard as possible."

As we have slowly come to understand, deep-space missions are inherently difficult. Thus it is impossible to ever reduce the risk of failure to zero. With a space program built on occasional comprehensive missions, a simple mechanical failure (as with Galileo), or a breakdown with an uncertain cause (as with Mars Observer), or a 
budgetary problem (as with the Comet Rendezvous/Asteroid Flyby) can prematurely end-or at least seriously degrade- a large fraction of the nation's effort in planetary exploration. The most widely proposed solution to break this vicious cycle is to return to simpler, cheaper missions. With an assured, steady stream of small missions, occasional failures become, if not acceptable, at least tolerable.

Since early in the space program, NASA's astrophysics and space physics programs have built and flown a highly effective series of Explorer spacecraft. These low-to moderate-cost missions have transmitted a virtually continuous stream of important scientific data for more than three decades. NASA's earth science program recently instituted a similar series, the Earth Probes, to fill a comparable niche in its activities. Several attempts have been made over the last decade and a half to introduce a comparable line of small planetary missions. For a variety of reasons, these efforts have all failed. Undaunted, NASA recently proposed again to begin such a program, now called Discovery. Two small planetary missions, the Near-Earth Asteroid Rendezvous (NEAR) and Mars Pathfinder, received new starts in the FY 1994 budget as "Discovery" missions, although, as mentioned in the main report, they do not satisfy NASA's present guidelines for this program. Given this situation, the Space Studies Board charged its Committee on Planetary and Lunar Exploration (COMPLEX) to:

1. Examine the degree to which small missions, such as those fitting within the constraints of the Discovery program, can achieve priority objectives in the lunar and planetary sciences;

2. Determine those characteristics, such as level of risk, flight rate, target mix, university involvement, technology development, management structure and procedures, and so on, that could allow a successful program;

3. Assess issues - such as instrument selection, mission operations, data analysis, and data archiving - to ensure the greatest scientific return from a particular mission, given a rapid development schedule and a tightly constrained budget; and

4. Review past programmatic attempts to establish small planetary science mission lines, including the Planetary Observers and Planetary Explorers, and consider the impact management practices have had on such programs.

In the course of its deliberations, COMPLEX found that rather than representing a fall from past glories, the initiation of a series of small missions presents the planetary science community with the opportunity to expand the scope of its activities and to develop the potential and inventiveness of its members in ways not possible within the confines of large, traditional programs. Some researchers may use the opportunities raised by a program of small missions to enhance or augment comprehensive studies of particularly interesting objects such as Mars and Jupiter. Others may employ them to perform reconnaissance of classes of relatively unknown objects such as comets and asteroids, to pursue aspects of intensive study of the terrestrial planets and the Moon, or to investigate planetary phenomena from Earth orbit. The rapid development schedules achievable with small missions should allow the possibility of exploiting targets of opportunity, should permit greater use of current technology, and should enhance the involvement of all sectors of the educational system in space research.

COMPLEX also realized, however, that a program of small planetary missions (such as Discovery) was, in and of itself, incapable of meeting all of the prime objectives contained in its report An Integrated Strategy for the Planetary Sciences: $1995-2010 .^{1}$ As explained in that report, a responsive planetary exploration program demands a mix of mission sizes ranging from comprehensive missions with multiple objectives (such as Galileo and Cassini) to small missions with highly constrained scientific objectives.

For a program of small planetary missions to fulfill its promise, COMPLEX believes that it must satisfy certain criteria. These include the following:

1. A continuing budget line should be initiated that is dedicated to a series of small planetary missions that focus on specific, well-defined objectives and are capable of yielding significant scientific results. The chosen missions should address key scientific questions and objectives as outlined in the report An Integrated Strategy for the Planetary Sciences: 1995-2010.

2. This budget line for small planetary missions should be funded at a level that will permit the launch of at least one mission per year, with approximately half of the accepted missions supported at a level close to the currently announced budget cap of \$150 million (FY 1992 dollars), not including inflation. 
3. Each mission must be selected through open competition from proposals presented as an integrated package by a principal investigator. This individual should have full authority to decide the appropriate balance among science performance, mission design, and acceptable risk.

4. NASA should not impose on mission design arbitrary constraints such as preselection of launch vehicle, spacecraft bus, payload, or data rate, nor should NASA specify a particular management structure or a specific institution to run mission operations.

5. The budget, schedule, and risk envelope must be identified in the conceptual and definition phase of mission planning. It is essential for NASA to adhere to the agreed-upon funding profile.

6. Past NASA practices must change in order to foster the development of a streamlined approach to management of each complete mission.

7. As soon as they have been calibrated and validated, data and all subsidiary information (e.g., spacecraft ephemerides) needed for their interpretation should be archived expeditiously to ensure their prompt availability to the entire research community.

8. NASA's Planetary Instrument Definition and Development Program should be augmented to produce highly capable science instruments that are appropriate for use in the Discovery program.

9. The option of using elements of the small-mission philosophy for Mars Surveyor and future large missions should be studied.

\section{REFERENCE}

1. Space Studies Board. National Research Council, An Integrated Strategy for the Planetary Sciences: 1995-2010, National Academy of Sciences, Washington, D.C., 1994. 


\section{Background and Current Environment}

In the 1960 s and early 1970 s, planetary science was carried out by small spacecraft in modest programs, such as Mariner and Pioneer. These programs were highly successful and revolutionized our knowledge and understanding of the planets. As a result, more complicated spacecraft with more ambitious objectives were constructed. Many of these (e.g., Viking, Voyager, Magellan, and others) were also spectacularly successful. However, the evolution from small to large missions, coupled with shrinking budgets, led to increased time between missions and thus fewer opportunities for innovation and discovery. ${ }^{1}$

The excessive reliance on large missions in the late 1970s and 1980s has been unhealthy for planetary science. Missions are few and far between, and failures-when they occur-threaten the entire planetary science program. Moreover, the budgetary challenges facing our nation mandate that the future exploration of the solar system will be increasingly constrained. Large and complex missions that address a broad range of scientific objectives, such as Galileo and Cassini, despite their virtues, will be flown less often, if ever. To address these problems, NASA is seeking to establish small-mission programs, two examples of which are Discovery and Mars Surveyor (see Box 1.1 for a discussion of the relative cost of large and small planetary missions). The implementation of a program of focused, small planetary missions in the context of a balanced approach to solar system exploration has advantages not only for science, but also for education and technological development.

Other disciplines such as astrophysics, space physics, and earth science have successfully established smallmission programs. Perhaps because interplanetary (deep-space) missions are often more challenging than Earthorbiting missions, attempts to develop a comparable line of small planetary missions have not succeeded. The Planetary Observer program of the early 1980s was the most public attempt by NASA to initiate a continuing, small-mission planetary line, but it was not approved by the Office of Management and Budget and Congress. Mars Observer, which was to be the first of this series, overran its initial budget by a large factor, for various reasons, including a changing external environment and NASA mismanagement, 2,3 and no subsequent Observer missions were flown.

A primary problem of a planetary program that consists only of large missions is that risk becomes unmanageable. The great cost and importance of any single mission encourage NASA to apply expensive procedures (e.g., redundancy, complex "fail-safe" software, backup spacecraft, superfluous tests, and excessive review) in an endeavor to mitigate risk. Such attempts to eliminate risk have greatly increased the cost of large missions, without clearly increasing their reliability, as Galileo and Mars Observer have demonstrated. The avoidance of risk also leads to engineering conservatism, which has delayed the introduction of some promising technical 


\section{Box 1.1 Mission Cost}

Comparing the cost of one space science mission to another is an endeavor replete with pitfalls. Besides relatively simple factors such as changing inflation rates, what should and should not be included in a mission budget? Among the costs that could, and perhaps should, be legitimately included are those for spacecraft development, the launch vehicle, tracking, mission operations, and data analysis, but this approach has not always been taken. Indeed, practices have changed over the years, and it is difficult for non-experts to know if they are comparing apples with apples or apples with apples and oranges.

COMPLEX, a committee with expertise in the planetary sciences, clearly identifies itself as non-experts when it comes to discussions of mission costs. The committee recognizes, however, that no consideration of the merits of small missions is complete without a clear understanding of what "small" actually means. The basic question, of course, is how many Discovery missions are equivalent, financially, to a Magellan or a Galileo?

With no special expertise in mission economics, COMPLEX has instead gathered data from people who are experts. Between 1988 and 1994, for example, the General Accounting Office and the Congressional Research Service issued a number of reports analyzing the costs of NASA planetary missions.* Reconciling the data in these disparate reports would, however, be a study in its own right. The same could be said about any attempt to reconcile other independent analyses of mission costs. To avoid these problems, COMPLEX requested relevant data directly from NASA's Office of Space Science. The figures shown in Table 1.1 are all in 1994 dollars and are calculated in such a way that the cost of one mission can be compared directly with the costs of others. Mission operations costs are also given for each of these missions.

\footnotetext{
"General Accounting Office, Space Exploration: Cost, Schedule, and Pertormance of NASA's Magellan Mission to Venus, NSIAD-88130FS, Washington, D.C., May 1988; General Accounting Otfice, Space Exploration: Cost, Schedule, and Performance of NASA's Mars Observer Mission, NSIAD-88-137FS, Washington, D.C., May 1988; General Accounting Office, Spece Exploration: Cost Schedule, and Performance of NASA's Gallieo Mission to Jupiter, NSIAD-88-138FS, May 1988; General Accounting Offlce, Space Exploration: Cost, Schedule, and Pertomance of NASA's Ulysses Mission to the Sun, NSIAD-88-129FS, Washington, D.C., May 1988; General Accounting Office, Space Science: Causes and Impacts of Cutbacks to NASA's Outer Solar System Exploration Missions, NSIAD-94-24, Washington, D.C. December 1993; General Accounting Office, NASA Program Costs: Space Missions Require Substantially More Funding Than Initially Estimated, NSIAD-93-97, Washington, D.C., December 1992; and Congressional Research Service, Library of Congress, Big Science and Technology Projects: Analysis of 30 Selected U.S. Govemment Projects, 94-687 SPR, Washington, D.C., December 7, 1994.
}

advances into planetary missions and may have been partly responsible for the 1992 cancellation of the Comet Rendezvous/Asteroid Flyby (CRAF) mission.

The scarcity of opportunities, which is a direct consequence of the increased cost and high risk of large missions, leads to even more complex missions. If there will be only one mission to a given planet in many years, scientists insist that it answer as many questions as possible. Thus missions are ambitious, with an array of instruments, high data-transmission rates, and complicated mission profiles. This in turn raises risk, complexity, and cost, ensuring that future mission opportunities will be scarce.

As mentioned above, the idea of establishing a line of small, low-cost planetary probes is far from new. It is worthwhile to recall the circumstances of three previous attempts to develop small missions (Planetary Explorer, Planetary Observer, and Lunar Scout) and three current examples of low-cost deep-space missions (Clementine, Discovery, and Mars Surveyor).

\section{PLANETARY EXPLORER}

In 1968, the Space Science Board recommended "that NASA initiate now a program of Pioneer/Interplanetary Monitoring Platform-class spinning spacecraft for orbiting Venus and Mars at each opportunity, and for explor- 
TABLE 1.1 Mission Cost

\begin{tabular}{|c|c|c|c|}
\hline Program & $\begin{array}{l}\text { Total Cost } \\
\text { (1994 \$ million) }\end{array}$ & Mission Summary & Launch Date \\
\hline Mariner Mars ' 71 & 489.7 & 2 orbiters ( 4 instruments) & May 1971 \\
\hline Operations & 94.1 & & \\
\hline Mariner Mercury-Venus ' 73 & 366.1 & 1 spacecraft ( 6 instruments) & March 1973 \\
\hline Operations & 27.2 & & \\
\hline Pioneer 10,11 & 351.6 & 2 spacecraft ( 11 instruments) & March 1972 and April 1973 \\
\hline Operations & 50.8 & & \\
\hline Viking & 3282.6 & $\begin{array}{l}2 \text { orbiters ( } 4 \text { instruments), } \\
2 \text { landers ( } 13 \text { instruments) }\end{array}$ & August 1975 and September 1975 \\
\hline Operations & 116.3 & & \\
\hline Voyager & 807.7 & 2 spacecraft ( 13 instruments) & August 1977 and September 1977 \\
\hline Jupiter and Saturn operations & 160.1 & & \\
\hline Uranus operations & 159.9 & & \\
\hline Neptune operations & 135.7 & & \\
\hline Pioneer Venus & 444.7 & $\begin{array}{l}1 \text { orbiter ( } 12 \text { instruments), } \\
1 \text { probe bus ( } 2 \text { instruments), } \\
1 \text { large probe ( } 7 \text { instruments), } \\
\text { and } 3 \text { small probes } \\
(3 \text { instruments) }\end{array}$ & May 1978 and August 1978 \\
\hline Operations & 35.1 & & \\
\hline Magellan & 625.1 & 1 orbiter ( 3 instruments) & May 1989 \\
\hline Operations & 118.3 & & \\
\hline Galileo & 1478.2 & $\begin{array}{l}1 \text { orbiter ( } 11 \text { instruments), } \\
1 \text { probe ( } 7 \text { instruments) }\end{array}$ & October 1989 \\
\hline Operations & 491 & & \\
\hline Mars Observer & 617 & 1 orbiter (7 instruments) & September 1992 \\
\hline Operations & 41.8 & & \\
\hline Near-Earth Asteroid Rendezvous & 145 & 1 spacecraft ( 6 instruments) & February 1996 \\
\hline Operations & 38.4 & & \\
\hline Mars Global Surveyor & 131.2 & 1 orbiter (6 instruments) & November 1996 \\
\hline Operations & 22.7 & & \\
\hline Mars Pathfinder & 167.5 & 1 lander ( 3 instruments) & December 1996 \\
\hline Operations & 14.9 & & \\
\hline Cassini & 1424.1 & $\begin{array}{l}1 \text { orbiter ( } 12 \text { instruments } \\
\text { plus } 2 \text { instruments for European } \\
\text { Space Agency probe) }\end{array}$ & October 1997 \\
\hline Operations & 490 & & \\
\hline
\end{tabular}

SOURCE: Data from Wesley Huntress, Jr., Associate Administrator, Office of Space Science, NASA. 
atory missions to other targets." 4 Subsequent studies conducted by NASA, industrial contractors, and the planetary science community led to the concept of a low-cost, spin-stabilized Planetary Explorer spacecraft. This universal bus, following a Delta launch, could deploy a variety of scientific payloads, including atmospheric probes, landers, or orbiters.

Planetary Explorer received a major endorsement in Venus: Strategy for Exploration (the so-called "Purple Book"), issued by the Space Science Board in June 1970. That report recommended that the Planetary Explorer concept be used "as the prime vehicle for the initial exploration of Venus ...."

Simple, low-cost missions have obvious attractions. Those enunciated by the 1970 report included the following:

- A series of missions can be planned;

- High-risk experiments offering high-scientific return can be undertaken;

- The participation of, and collaboration between, many scientists and scientific disciplines would be enhanced;

- International cooperation would be promoted;

- Education would be furthered through the participation of "less senior experimenters--even ... graduate students under supervision"; and

- Programmatic flexibility would be strengthened in times of rapid scientific advance and/or fiscal uncertainty.

Low cost would be encouraged by:

- Keeping paperwork to a minimum;

- Avoiding "complex mechanisms" unless there is a definite scientific requirement;

- Standardizing hardware to the maximum extent possible; and

- Having NASA accept a greater level of risk than in previous planetary missions.

The Purple Book outlined a series of Planetary Explorers to be sent to Venus at every launch opportunity in the period from 1975 to 1980 . The first mission would consist of a bus carrying four (one large and three small) atmospheric probes and would be followed by an orbiter, a lander, and finally an atmospheric probe equipped with balloons. In November 1971, NASA discontinued work on Planetary Explorer at Goddard Space Flight Center for programmatic reasons and transferred it to Ames Research Center, where it continued under the new name Pioneer Venus. No subsequent Planetary Explorers were built.

Unfortunately, what the Space Science Board had envisaged as a low-cost program using tried and true instruments and an innovative approach to management, rapidly "crystallized as a single opportunity mission-a Multiprobe and an Orbiter that reflected significant and major advances in the sophistication of spacecraft and their instrumentation. ..." These missions received a new start in FY 1975, and, after surviving a number of developmental problems, serious budgetary crises, ${ }^{7}$ and threats of cancellation, Pioneer Venus 1 (Orbiter) and Pioneer Venus 2 (Multiprobe) were launched on May 20 and August 8, 1978, respectively.

The atmospheric probes returned data on December 9, 1978, as they descended through Venus's atmosphere for almost an hour. Five days earlier, the Pioneer Venus Orbiter had settled into an elliptical orbit about the planet. Although designed to operate for only 2 years, it continued radioing data back to Earth until October 8, 1992.

\section{PLANETARY OBSERVER}

The most prominent attempt to initiate a series of low-cost planetary science missions was made by NASA's Solar System Exploration Committee (SSEC) in the early 1980s as part of an effort to develop a stable and affordable mission strategy during a period of budgetary scarcity. ${ }^{8}$ These small missions were to be called "Observers" and were intended to have much the same character as today's Discovery missions.

These missions (primarily planetary orbiters) would take advantage of modified versions of production-line Earth-orbital platforms and use mature instrumentation. The missions were to be managed by a NASA center and 
the science payloads to be selected in the traditional manner in response to a competitive Announcement of Opportunity. The launch vehicle designated by the national launch policy of the time was the space shuttle.

In practice, what seemed like a modest innovation in approach turned out to be a continuing problem and, ultimately, a technical failure. The payload selected was too ambitious for a low-cost mission. The competitively selected spacecraft for Mars Observer required much more modification from production-line, commercial, Earthorbital systems than anticipated. At the same time, the fixed-price contract lacked the flexibility to allow the changes needed as the mission evolved, primarily due to external factors. A switch in launch vehicle (to a Titan III), resulting from the Challenger disaster, caused major technical revisions, changes in risk mitigation policies, painful descoping of the payload, ${ }^{9}$ and a costly schedule delay that compounded all of the above problems. Further, the budget available to the project was driven significantly by external factors during the several years in which NASA's space science program was reconstituted in the post-Challenger years.

The first Observer mission-the Mars Geoscience/Climatology Orbiter, later renamed Mars Observer-was also the last. This outcome had become clear as costs escalated during the period of mission redesign following the loss of Challenger. Plans to follow the first mission with a Lunar Observer using a similar payload were shelved (see the section "Lunar Scout" below), as were proposals to employ this Moon-bound spacecraft as a backup for the Mars mission. Standing on its own, the Mars Observer project was required to acquire spare systems to provide insurance against the possible failure of the (as yet untested) upper-stage launcher or of the spacecraft itself; this requirement added significantly to costs. Ironically, when Mars Observer was in fact lost just before its scheduled insertion into Mars orbit in August 1993, NASA decided not to use the spares to rebuild the spacecraft (although major components of Mars Observer will be used by Mars Surveyor missions).

The Mars Observer Failure Review Board's report ${ }^{10}$ listed many general concerns (some of which are mentioned above), including top-level systems engineering and management inadequacies, as well as specific technical problems, that were probable sources of the loss. One of the principal lessons learned was that too much reliance was placed on the heritage of the spacecraft's hardware, software, and procedures. This approach was inappropriate, given that the spacecraft was fundamentally different from the Earth-orbiting weather satellites from which Mars Observer and, thus, its heritage were derived. Another lesson learned was the failure of Mars Observer's manufacturer to make the best use of the Jet Propulsion Laboratory's experience in building planetary spacecraft. The Review Board also criticized the static nature of the mission's acquisition and management strategy even as Mars Observer evolved from the first in a series of Planetary Observers to a unique mission. The Review Board recommended that "many of these concerns should be carefully considered by NASA management, since they have the potential to affect future spacecraft developments and operations." Indeed, it is clear that the numerous lessons learned-by NASA, by industry, and by the science community-from the failed Observer experiment should be applied to all new deep-space programs, and especially to those that are substantially costconstrained.

\section{LUNAR SCOUT}

The detailed exploration of the composition and geophysics of the Moon has long been of high priority in the planetary science community. Besides being an object of purely scientific interest, the Moon is an obvious target for future voyages by astronauts. Political and budgetary complications arising from interactions between human exploration and scientific goals profoundly influenced the Ranger, Surveyor, and Lunar Orbiter programs in the $1960 \mathrm{~s}^{11}$ and, more recently, led to the collapse of a proposed series of small lunar science missions.

In the 1970 s, the preferred way to augment the data gathered by the early lunar robotic probes and by the Apollo missions was to place a satellite equipped with sophisticated remote-sensing instruments into polar orbit about the Moon. The proposed mission, the Lunar Polar Orbiter, was complex and expensive, and it never was flown for a variety of programmatic reasons, including cost. The Planetary Observer program (see above) offered a new opportunity to initiate more modest lunar science missions. When the Observer line ended with Mars Observer, a proposal was made to create a Lunar Observer using spare Mars Observer hardware. This craft, like its martian counterpart, was, however, in the $\$ 500$-million-plus price range. 
The Space Exploration Initiative (SEI), put forward by then-President Bush in 1989, created new pressures to gather the lunar science data needed to support the planned extensive program of human exploration. Adding the necessary instruments to the proposed Lunar Observer raised its cost to $\$ 1$ billion or more. A more modest plan, utilizing a series of small, low-cost orbiters (Lunar Scout) and less well defined landers (Artemis), was adopted by NASA's Office of Exploration. COMPLEX assessed the proposed payloads of the first two Lunar Scouts and found them generally responsive to the priorities for lunar science stated in the committee's past reports. ${ }^{12}$ Although the Lunar Scouts had a sound scientific foundation, political support for an expensive human exploration program and anything relating to it was absent. The Lunar Scout and Artemis programs collapsed when funding for the SEI failed to materialize and the Office of Exploration was disbanded.

\section{CLEMENTINE}

The only recent, completed example of an approach to substantially reduce the cost of deep-space probes has been Clementine, a technology-demonstration mission sponsored by the Ballistic Missile Defense Organization. ${ }^{13}$ NASA participation in the mission was limited to communications support, scientific advice on the mission design, and analysis of the data collected. Clementine was built by the Naval Research Laboratory and carried an instrument payload of 7 kilograms, including ultraviolet-visible imagers, near- and long-wavelength infrared cameras, and a laser altimeter. Following launch on a refurbished Titan $2 \mathrm{G}$ intercontinental ballistic missile on January 25, 1994, Clementine was placed into a polar orbit around the Moon a month later.

Although it successfully completed three months' worth of lunar measurements, along with many of its technical goals, a software error triggered an uncontrollable spin and Clementine was unable to make the transfer maneuvers necessary to fly past the near-Earth asteroid 1620 Geographos. As a result, Clementine did not have the opportunity to attempt one of its major technical goals, the autonomous acquisition of a moving target. Despite this failure, the mission was viewed in the popular press as a success; it is interesting to speculate whether a NASA mission that did not achieve an important objective would have been treated as favorably.

Clementine must in COMPLEX's view be counted as a practical demonstration of a quick, low-cost mission, even though it was not driven by science. The lessons learned in this mission need to be probed to a greater depth than is possible in this report; only then can they guide the success of other low-cost missions. ${ }^{14}$

\section{DISCOVERY AND MARS SURVEYOR}

Two programs for a series of planetary missions with limited objectives, Discovery and Mars Surveyor, are currently under development. NASA received new starts in FY 1994 for a pair of small missions: Near-Earth Asteroid Rendezvous (NEAR) and Mars Pathfinder, which were called "Discovery" missions although they do not now satisfy current guidelines for this program. NEAR, which is to be launched in February 1996, will rendezvous with the near-Earth asteroid 433 Eros for a year starting in December 1998. This mission will carry 55 kilograms of remote-sensing instruments, including a visible imager, a near-infrared spectrograph, a laser altimeter, and $\mathrm{x}$ and gamma-ray spectrometers. These will be used to determine the asteroid's surface geology and, insofar as possible without in situ measurements, its bulk properties and composition. The spacecraft is being built and managed by the Johns Hopkins University's Applied Physics Laboratory.

Mars Pathfinder, which is being constructed by NASA's Jet Propulsion Laboratory, will serve as a science and engineering test of the entry, descent, landing, and deployment systems for future small Mars landers. Its payload includes a microrover (supplied by NASA's Office of Space Access and Technology), an imaging system, and devices for assaying the local soil. The instrument packages for both Clementine and NEAR are all facility instruments and were preselected, as was the Pathfinder concept, and so none of these missions fully satisfies the mission concept that the committee considers below.

NASA has proposed that NEAR and Mars Pathfinder form the start of a new program, the Discovery program, whose stated goals are to "increase flight rates and launch certainty, complement large missions to keep a steady rate of incoming planetary data, broaden university and industry participation in solar system exploration missions, and increase public awareness of solar system exploration missions." 15 This proposed program envisages a 
range of missions and targets. NASA's FY 1996 budget proposes a new start for a third Discovery mission, Lunar Prospector. The status of this mission was uncertain at the time this report was written.

The Mars Surveyor program, which received approval in the FY 1995 budget, is conceived to be a series of low-cost missions (both orbiters and landers) that are concentrated on the Red Planet, a particularly high-priority target. According to current plans, the first phase of this program will involve the launch of a low-cost orbiter, Mars Global Surveyor, equipped with a subset of Mars Observer's instruments, in November 1996. Some 10 months later, the spacecraft will employ aerobraking to place itself in a Sun-synchronous orbit about Mars. The second phase of the Mars Surveyor program will occur some 26 months later, with the launch of an additional orbiter possibly carrying some of the remainder of Mars Observer's payload, and a small lander, possibly derived from Mars Pathfinder. Subsequent missions, involving a separate orbiter and lander, will follow at each possible launch opportunity. The landers, possibly deployed in concert with international partners, will address strongly focused science objectives, such as assessing the distribution of water at the surface of Mars, determining the planet's interior structure, or seeking clues of past climatic changes in the mineralogy of weathered products.

For this report, COMPLEX did not further consider the Mars Surveyor program because, at least in its initial stages, it will not be run by principal investigators (PIs), as COMPLEX believes other small programs should be. In addition, its later (i.e., lander) stages are not currently defined in sufficient detail to assess fully. Nevertheless, many of the observations made below in this document also apply to this program. COMPLEX recommends that the option of using a lead-PI approach to later Mars Surveyor missions be studied. The question of whether Discovery missions to Mars should compete within the Mars Surveyor program needs additional review.

\section{REFERENCES}

1. NASA Advisory Council, Space and Earth Science Advisory Committee, The Crisis in Space and Earth Science, NASA, Washington, D.C., 1986.

2. Polk, Charles, Mars Observer Project History, NASA-Jet Propulsion Laboratory. Pasadena, Calif., 1990.

3. Travis, John, and Cohen, Jon, "Mars Observer's Costly Solitude," Science 261, pages 1264-1267, September, 31993.

4. Space Science Board, National Research Council, Planetary Exploration 1968-1975, National Academy of Sciences, Washington, D.C., 1967, page 5.

5. Space Science Board, National Research Council, Venus: Strategy for Exploration, National Academy of Sciences, Washington, D.C., 1970, page 1.

6. Fimmel, Richard O., Colin, Lawrence, and Burgess, Eric, Pioneer Venus, NASA SP.416, NASA, Washington, D.C., 1983.

7. Comptroller General of the United States, National Aeronautics and Space Administration Should Provide the Congress with More Information on the Pioneer Venus Project, General Accounting Office, PSAD-77-65, Washington, D.C., 1977.

8. National Aeronautics and Space Administration, Solar System Exploration Committee, Planetary Exploration Through Year 2000: A Core Program, Government Printing Office, Washington, D.C., 1983.

9. Space Science Board, National Research Council, Letter report regarding an assessment of the impact on integrated science return from the 1992 Mars Observer mission, from the Committee on Planetary and Lunar Exploration to Geoffrey A. Briggs, NASA, July $12,1988$.

10. Mars Observer Failure Investigation Board, Report of the Mars Observer Failure Investigation Board, NASA, Washington, D.C., 1994.

11. Space Studies Board, National Research Council, Science Management Strategies for the Human Exploration of Space, in preparation.

12. Space Studies Board, National Research Council, Scientific Assessment of Proposed Robotic Lunar Missions of NASA's Office of Exploration, Letter report from Committee on Planetary and Lunar Exploration to Michael D. Griffin (NASA), August 21, 1992.

13. Nozette, S., et al., "The Clementine Mission to the Moon: Scientific Overview," Science 266, pages 1835-1839, December 16, 1994.

14. Space Studies Board, National Research Council, Lessons Learned from the Clementine Mission, National Academy Press, Washington, D.C., 1995, in preparation.

15. National Aeronautics and Space Administration, Solar System Exploration Division, Discovery Program Handbook, NASA, Washington, D.C., 1992, page 1. 


\section{The Small-Mission Concept}

\section{EXPLORERS IN ASTROPHYSICS, SPACE PHYSICS, AND EARTH SCIENCES}

In all disciplines of the space sciences except planetary exploration, scientific problems currently are addressed by missions that range in cost and complexity from small to large. Thus in astrophysics, projects with narrow objectives and limited lifetimes (e.g., the Submillimeter Wave Astronomy Satellite) exist side by side with other projects that are of higher cost and extended lifetimes (e.g., the Hubble Space Telescope). Similarly, NASA's major thrust in terrestrial studies-the comprehensive Earth Observing System-is complemented by missions with focused goals that fall under the Earth Probes budget line. Examples of the latter include the planned Total Ozone Mapping Spectrometer and the Tropical Rainfall Measuring Mission.

Generally speaking, the Explorer line is judged to be a success. According to a 1986 report by the Committee on Space Astronomy and Astrophysics, "the Explorer program has established an outstanding record of scientific accomplishments in a variety of space science fields including astronomy and astrophysics, space plasma physics, and solar physics" and "there is no doubt that the Explorer program has resulted in outstanding scientific discoveries and continues to contribute in a vital way to the progress of space research." 1 These conclusions reflect those of an earlier assessment by the Committee on Solar and Space Physics, which commented that "science ideas of high priority can be addressed with Explorers" and that "a high frequency of flight opportunities is warranted." Moreover, the record of the past and plans for the near future testify to the high quality of innovative science that is achieved by peer-selected Explorer missions. The primary complaint from these communities is that flights are much too scarce compared with the numerous scientific problems that can be addressed by low-cost missions. This problem has been exacerbated in these disciplines because many Explorers have exceeded the original guidelines of the program in terms of development schedule and funding limits. ${ }^{3-5}$

\section{SMALL MISSIONS IN PLANETARY EXPLORATION}

In view of the success that other space science disciplines have enjoyed with low-cost missions having specific scientific, technical, and programmatic guidelines, COMPLEX addressed whether such missions are also appropriate for planetary exploration. In particular, COMPLEX considered how NASA's proposed Discovery program can be designed to bring the benefits of small missions to the planetary science program.

At the outset COMPLEX notes that NASA has not yet established a program for low-cost planetary missions. Thus, any assessment of the scientific viability of such a program becomes problematic, because the full scope and 
scientific potential of missions satisfying these cost and time constraints remain uncertain. Nevertheless, the completed Clementine mission and the development of the NEAR and Mars Pathfinder missions provide some calibration as to the level of the returned science that might be expected from small planetary missions.

Examples of typical programs that may be possible under the general heading of small planetary science missions include Earth-orbital telescopes, flyby or orbital missions, and in situ sampling probes. How these small missions can be utilized to address the primary objectives outlined in COMPLEX's Integrated Strategy ${ }^{6}$ is also discussed below. The list of possible mission types is not comprehensive, nor is it intended to imply any special priority for the topics discussed.

Earth-orbital missions with planetary science objectives could carry out a variety of spectroscopic and imaging observations of solar system bodies, as well as contribute to the search for extrasolar planets. For example, the Earth-orbiting Infrared Astronomical Satellite (IRAS) and the International Ultraviolet Explorer (IUE), while not specifically designed for planetary studies, have made significant contributions to our knowledge of the solar system. Telescopes in Earth orbit are able to observe in wavelength regions (e.g., ultraviolet and infrared) unavailable to ground-based observatories owing to atmospheric absorption. Moreover, moderate-size Earthorbital telescopes can achieve spatial resolutions better than those possible with ground-based telescopes, whose images are degraded by atmospheric turbulence; adaptive optics could, when fully mature, lessen this advantage. Requirements for observing solar system objects are often inconsistent, to some degree, with the operation of large, general-purpose astrophysical observatories such as the Hubble Space Telescope. Frequently, these large observatories operate under constraints that prevent observations of some solar system targets and make continuous surveillance of time-variable phenomena difficult. For these reasons, Earth-orbital telescopes dedicated to solar system targets hold promise for achieving significant advances, while still meeting the goals of a low-cost, rapid-development, and focused program. The scientific benefits and the engineering feasibility of Earth-orbital missions have been amply proven by the Explorer line in astrophysics and space physics.

Various flyby and orbital missions to solar system targets-planets, satellites, asteroids, and comets-will also be possible in a small-missions program. Indeed, many proponents of the Discovery approach hold that this type of mission actually promises the greatest science return for the funds invested. This class of mission can address significant issues such as the surface composition of rocky bodies, interior structure, geologic evolution (including impact history), studies of particles and fields, and the composition, dynamics, and thermal structure of atmospheres. The Clementine and NEAR missions fall into this class. Since these latter missions have returned or will likely return valuable data, they suggest the level of science that can be accomplished within the confines of a small-missions program.

Many outstanding questions about the origin, evolution, and structure of atmospheres recognized in COMPLEX's Integrated Strategy can be addressed by small missions that make in situ measurements. These include determination of rare-gas and isotopic abundance ratios, measurement of atmospheric winds, specification of horizonal and vertical temperature profiles, and examination of atmospheric chemistry. In the past, such observations were made as part of larger multipurpose missions (e.g., Viking and Pioneer Venus). It may be a challenge to the innovation of the proposers of low-cost missions to provide comparable types of in situ instruments within the confines of a small-missions program. For example, will atmospheric sampling missions be restricted to inner solar system bodies, and are in situ measurements of solid surfaces possible to accomplish at all within the Discovery constraints?

Although it is clearly harder to fit sampling missions and flights to the outer solar system into Discovery's $\$ 150$ million cost envelope, innovative ways to achieve these objectives may be attainable. Accordingly, since an important purpose of the Discovery program is to challenge technology, it is essential that such projects be considered in any open competition for funds in a small-missions program.

\section{RELATIONSHIP TO INTEGRATED STRATEGY}

Many of the ideas that have been proposed for small missions address widely recognized, fundamental objectives in solar system science and can answer key questions outlined in COMPLEX's Integrated Strategy. In this section COMPLEX considers whether small missions can accomplish priority objectives at those targets 
highlighted by the Integrated Strategy: comets, Mars, Jupiter, and the search for extrasolar planets. As an example, the Integrated Strategy strongly recommends the detailed study of primitive bodies, especially comets. Small, lightweight spacecraft, built and operated under tight budgets, are well suited to rendezvous missions with such bodies, especially those on orbits that approach the Earth's. A mission that would fly alongside a comet, much as NEAR will do for an asteroid, can be envisaged.

The highest-priority science for primitive bodies is detailed determination of bulk composition, which can then be used to delimit possible origin scenarios. Composition can be well constrained by remote sensing, but sample analysis-whether in situ or by returned materials - may be required for definitive results. Cometary missions ranging in complexity from coma analysis, through penetrators and coma sample return, and ultimately to surface sample return may be proposed or attempted as small missions; some of these may turn out to be too expensive to be executed as small missions. COMPLEX recalls that the return of a sample of a solar system body for analysis in terrestrial laboratories has been achieved-and then at tremendous expense-only by the U.S. Apollo and Soviet Luna programs.

The continued study of Mars is another major priority of the Integrated Strategy. Small spacecraft with focused payloads could be employed to observe Mars from orbit. Remote sensing and compositional mapping of the surface, determination of atmospheric circulation and water vapor and dust transport, gravity and topography measurements, and aeronomy are important scientific goals that can be addressed in this way. Many of these issues were to be investigated by Mars Observer and may now be studied by the orbital component of the Mars Surveyor program. In addition, by deploying small landers, Mars Surveyor will focus on other high-priority science questions. Small, inexpensive landers-particularly if launched in clusters in cooperation with international partners-can address fundamental questions of Mars science.

But small missions alone will not fulfill all the major science objectives for Mars. Some important objectives, as stated by COMPLEX, are studying Mars's climate history, chronology, and the evolution of possible organic compounds. These studies appear to require the use of instrumentation and technology (e.g., sample return and long-range rovers capable of complicated in situ analyses) incompatible with a small-missions approach. Nevertheless, most detailed exploration will require preliminary surveys, which are well suited to small missions.

The Jupiter system (the planet, its magnetosphere, rings, and satellites) constitute the third high-priority target within our solar system, according to the Integrated Strategy. The distance and flight time to Jupiter may hinder implementation of a small-mission approach. However, some flyby missions to the jovian system may yield sufficient science, post-Galileo, to justify their cost. ${ }^{7}$ Moreover, Earth-orbiting telescopes may be effective in providing answers to some important questions. Nevertheless, the most significant advances in understanding the jovian satellites, rings, magnetosphere, or atmosphere (excluding probe studies) will likely require orbiters or landers, either of which would add substantially to mission duration, complexity, and price.

To some degree, the choice of priorities in the Integrated Strategy reflects an integration of important scientific questions posed by complex planetary targets, notably Mars and the Jupiter system. Accordingly, an individual small mission, with its strongly focused science objectives, can address only part of what the Integrated Strategy calls for at these two planets.

The Integrated Strategy set as its fourth priority the detection and study of circumstellar disks and extrasolar planets. Small Earth-orbiting observatories may make valuable contributions to this effort by, for example, being able to infer circumstellar material (as IRAS did) or to detect extrasolar planets. However, it is likely, although much less studied, that larger, more expensive projects (such as long-baseline interferometers in space or on the Moon) will be necessary to acquire the level of detail on planetary orbits and atmospheric compositions ultimately called for in COMPLEX's recent recommendation.

Before settling on the four priorities listed above, the Integrated Strategy surveys the major science issues across all solar system objects. This tabulation shows clearly that numerous important science questions exist outside the four main priority targets. In many cases, small missions are the most effective way to address these topics. From this perspective, a jovian-magnetosphere probe and a Mercury remote-sensing orbiter could, for example, be of comparable priority in a Discovery-type program.

It thus appears that small missions can yield a valuable science return, whether addressing the primary targets listed in the Integrated Strategy or some of the more specific objectives described in the same document. 


\section{THE NEED FOR A BALANCED PROGRAM IN PLANETARY AND LUNAR EXPLORATION}

The discussion above demonstrates that many high-priority scientific goals may be achievable with small missions. Nevertheless, as already described, not all high-priority scientific investigations fit within the restrictions of a small mission. For example, COMPLEX's Integrated Strategy report assigns its highest priority to the study of cometary nuclei, which ultimately will require a returned sample. Any sample return is an ambitious task, and previous plans to achieve this objective have been well outside the scope of a small mission. COMPLEX's Integrated Strategy also identifies the outer solar system (particularly, Neptune and Pluto/Charon) as the key to several questions about solar system origin and evolution. It is, in addition, fertile territory for studies of comparative planetology. Missions to the outer solar system will, however, require powerful launch vehicles and specialized power and communications systems. Therefore, unless these requirements are reduced as a result of technological innovation (e.g., development of new propulsion systems), small missions are not likely to contribute to this area of planetary science. Thus, it is to be expected that a small-missions program will emphasize the inner solar system.

Even if it does prove feasible to investigate the outer solar system through a small-missions program, it may not be cost-effective to do so-that is, the use of small missions does not assure that the most science will be returned per dollar spent, especially in the outer solar system. Because of the long flight times and different mission requirements (e.g., long-lived power sources and powerful transmitters) for spacecraft sent to the outer solar system, significant overall economy frequently can be achieved by maximizing the scientific return of any such mission. Almost by definition, large missions such as Galileo and Cassini carry a comprehensive set of instruments. For studying complex phenomena, simultaneous measurements with a variety of instruments are therefore possible on big missions, but frequently not with more focused missions. ${ }^{8}$ Cassini, for example, carries instruments that will measure the solar and magnetospheric energy input into Titan's atmosphere, the chemical composition of the satellite's atmosphere, the distribution of aerosols in the atmosphere, and the physical state of the surface. These attributes of Titan's atmosphere and surface are all interlinked; accordingly, great scientific value can accrue from well-coordinated, contemporaneous measurements.

Nevertheless, future comprehensive missions might benefit from application of some aspects of the philosophy of small missions, that is, use of streamlined management, innovative technology, and lightweight spacecraft. COMPLEX recommends that this approach be studied.

\section{ATTRIBUTES OF AN EFFECTIVE SMALL-MISSIONS PROGRAM FOR PLANETARY EXPLORATION}

Given that a program of small missions could play a valuable role in planetary exploration, what features should characterize such a program? Before listing desirable attributes, it is essential to stress that a reduction in mission scale must not be taken to imply any lessening in the quality of the science that must be produced: any space program should aim for nothing less than addressing the most important scientific objectives and use of the most capable instrumentation available, with missions being selected by fully open competition. The reason that care must be taken to ensure that only the highest-quality science is accepted is that, despite being less costly than most previous planetary spacecraft, Discovery missions still have significant costs so that, in a constrained budget, only very few will be flown.

A small-missions program is able to focus on specific, well-defined scientific objectives with the expectation that definitive results will be produced, using the minimum investment of scarce resources. This is an important virtue. An example might be analysis of the elemental composition of an asteroid surface, or precise measurement of trace constituents in a planetary atmosphere. Such experiments have traditionally been included as part of an instrument suite aboard a major mission but may prove more cost-effective if made the focus of a payload. For a population of solar system objects with significant interobject variability, such as asteroids or comets, any attempt to generate a comprehensive picture of the population would require a number of essentially identical, or very similar, missions; this requirement might be prohibitively expensive and/or complicated if fulfilled with typical planetary spacecraft but might become more practicable with small missions. 
A necessary corollary of utilizing small, focused missions to address planetary science goals is the requirement of a high flight rate. A high rate of flights is desirable from a scientific perspective because it allows the program as a whole to study a diverse set of targets. It is also desirable from a programmatic perspective as described in Chapter 3. A rate of one mission per year has been widely discussed in connection with the Discovery program and is strongly endorsed by COMPLEX.

Small planetary missions create an opportunity to introduce management structures that differ from those used in the traditional large missions. One approach that has proven efficient and successful for instruments in larger missions, as well as for whole missions in other fields, is to have the work controlled by an individual principal investigator (PI) who proposes the science objectives and the instrumental approach to achieve them. The PI is best able to decide how to make the inevitable trade-offs throughout the project that would be in the best interest of achieving the science objectives within budget constraints. Making such trade-offs will require rigorous cost and schedule control in order to fit within the cost cap and a minimum of one launch per year, essential elements of any small-missions program.

Small planetary missions can also bridge the programmatic gap between ground-based astronomy and more traditional deep-space missions. Small missions allow exploratory visits to close-by targets (such as the Moon) and smaller solar system objects, as well as the monitoring of temporal and spatial variability of the planets from Earth orbit. Furthermore, small missions can lay the groundwork for more comprehensive missions. In particular, ground-based observations, and indeed remote sensing from flyby missions (such as Giotto and Vega), have failed to provide the information about the physical properties of a comet nucleus that will be necessary input for the design of any comet-nucleus sample-return mission. A Discovery-class spacecraft could in principle supply such data, thus facilitating a more ambitious sample-return mission. By providing specific answers that may greatly elucidate previous information, small missions may also "fill in the gaps" left after larger programs have returned their data lode.

The relatively brief development time of small planetary spacecraft, as in the proposed Discovery program, makes it feasible to address targets of opportunity, whereas a traditional mission lacks the requisite flexibility. For example, a small mission might allow taking advantage of a particularly favorable arrangement of objects in space, or the opportunity to characterize more fully an unusual target, of which last year's impact of comet ShoemakerLevy 9 with Jupiter is a dramatic example.

Any small-missions program will provide a learning experience for the planetary community, industry, and NASA in what it takes to conduct successful low-cost missions. Although the choice of components (e.g., spacecraft bus) for such a mission must be left to the PI, a growing body of experience will be available to later proposers. Thus the scientific capabilities of small missions can be expected to grow with time, if, of course, rapid development, frequent launch rate, and steady funding are ensured.

Planetary science contributes to NASA's overall mission of providing knowledge and demonstrating technical achievements in space. However, lengthening intervals between traditional solar system missions have made it increasingly difficult to maintain a vital work force in planetary science. A high flight rate will do much to maintain the skilled, experienced cadre of engineers and managers that is essential for a successful program. By according primary responsibility to PIs at universities, as proposed for at least some missions in the Discovery program, NASA will enhance the educational and training programs at those universities. The first-hand experience that many students will gain within such a program will strengthen the nation's technical expertise. Such a decentralized mission organization, located within an educational institution, will lend itself to even more widespread outreach, extending beyond the university to K-12 education.

Finally, teaming among universities, industrial organizations, and NASA centers, as emphasized within the proposed Discovery program, will be useful in stimulating constructive interactions among those organizations. Clearly, cross-fertilization of this kind will benefit all partners and will increase the competitiveness of the U.S. space program. Furthermore, by fostering a management approach that is both interactive and more streamlined than has been customary in space research, a program of small missions can epitomize the new way of doing business within NASA.

In summary, the attributes of an effective small-missions program include the following: 
- The performance of the highest-quality science;

- The ability to address a broad spectrum of studies having tightly focused objectives;

- Reduced cost and fast turnaround;

- A high launch rate, preferably one per year; and

- Streamlined management with a principal investigator structure, minimized bureaucracy, and heightened cooperation among programmatic elements.

\section{REFERENCES}

1. Space Science Board, National Research Council, The Explorer Program for Astronomy and Astrophysics, National Academy Press, Washington, D.C., 1986, pp. 1 and 2.

2. Space Science Board, National Research Council, A Strategy for the Explorer Program for Solar and Space Physics, National Academy Press, Washington, D.C., 1984, page 5.

3. Board on Atmospheric Sciences and Climate and Space Studies Board, National Research Council, A Space Physics Paradox, National Academy Press, Washington, D.C., 1994. page 43.

4. Space Science Board, National Research Council, A Strategy for the Explorer Program for Solar and Space Physics, National Academy Press, Washington, D.C., 1984, page 9.

5. Space Science Board, National Research Council, The Explorer Program for Astronomy and Astrophysics, National Academy Press, Washington, D.C., 1986, page 7.

6. Space Studies Board, National Research Council, An Integrated Strategy for the Planesary Sciences: 1995-2010. National Academy Press, Washington, D.C., 1994

7. Science Applications International Corp., Measure-Jupiter Mission Design Book, Nasa-Jet Propulsion Laboratory, Pasadena, Calif., 1994.

8. Space Studies Board, National Research Council, "Scientific Assessment of the CRAF and Cassini Missions," letter report from the Committee on Planetary and Lunar Exploration to Lennard Fisk (NASA), March 30, 1992. 


\section{Technological and Programmatic Aspects}

\section{COST OF CAPABLE SMALL MISSIONS}

According to NASA's current guidelines, Discovery missions are budgeted at less than $\$ 150$ million (FY 1992 dollars) exclusive (at the time of writing) of launch vehicles and mission operations and data analysis, and are to be chosen from competitive, peer-judged proposals. Based on COMPLEX's preliminary evaluation of the Clementine mission, the NEAR mission now being executed, and the many Discovery-class concepts that were presented at a 1992 workshop, ${ }^{1} \$ 150$ million is a reasonable cost cap for limited-scope planetary missions capable of returning significant results. Yet it must be remembered that planetary spacecraft must be somewhat more sophisticated than those of other space science disciplines because they have to survive and transmit valuable data across interplanetary distances. Thus, COMPLEX believes that to accommodate the required broad spectrum of focused missions, a large fraction (approximately half) of the selected projects will need to be funded near this $\$ 150$ million level. Any attempt to impose a significantly lower cost cap would not be cost-effective because it would seriously impair the ability of the program to address important science goals.

It is vital that a high ratio of science return per dollar spent be maintained on all missions selected; it makes little sense to develop a mission merely because it is cheap. Since Discovery is proposed to be a long-standing program, the cost cap should increase with the relevant inflation rate; otherwise the scientific capabilities may be seriously compromised. Despite the obvious limitations of such a cost constraint, enthusiasm among planetary scientists for a program of this nature is high, judging by the many new, creative and innovative mission concepts proposed to date.

\section{THE NEED TO ESTABLISH A PROGRAM}

Although planetary exploration has largely been made up of a series of Mariner (including Voyager) and Pioneer missions to individual planets, there has not been any direct analogue to the Explorer program of missions that have served the space physics and astronomy communities so well for decades. Despite differing widely from one another in terms of scientific goals, instrumentation, and implementation approach, Explorer missions have constituted a continuing program in that they have been planned and carried out as a predictable line item in NASA's budget.

Especially for missions constrained to be implemented within fixed schedules and capped budgets-the premise of the Discovery program-one essential attribute is that NASA make, and keep, its commitments to 
provide a stated funding profile for the definition, design, and implementation phases; predictable budgets are the key to management effectiveness. When externally driven changes are minimized, full responsibility and accountability for mission success can remain with the principal investigator and the project manager, who are then better able to deliver a successful mission than in the current system where budget stability is rare.

It is the predictability of the program funding that will permit NASA's Office of Space Science the flexibility to plan a sequence of high-quality missions that together adequately address the scientific and other programmatic goals of solar system exploration. Moreover, managers will be in a much better position than otherwise to deal with occasional failures - of whatever kind-that are an inherent part of space exploration and a recognized element of the increased risk associated with small missions. A reflight of a high-priority small mission can be incorporated into the stream of missions at a point chosen to minimize the externally driven change so detrimental to disciplined program management.

Even though a small-missions program may include different types of missions to various solar system objects, the program should be treated as an integrated whole rather than as a series of discrete, independently funded missions. Funding of a continuing program is necessary for a cost-effective, rational, long-term plan. Most Discovery missions are expected to be short, no more than a few years in duration. The missions must be phased appropriately for the available resources to be used efficiently. The program approach would ensure that development of instruments for future missions, support of missions in their development phases, and funding of operations for nominal and extended missions are appropriately balanced against each other to ensure maximum return from the whole program. By appropriately sequencing missions and funding different mission phases, the program approach may also be used to maintain a level budget profile, rather than the pulsed profile that would normally develop if a series of missions were funded independently. Reserves would be managed in a manner most effective for preserving program goals. In addition, funding for the development of instruments would be judged within the context of overall program objectives, rather than the goals of specific missions.

Another important reason for initiating a line of Discovery missions is to ensure that flight opportunities are allocated on a competitive basis following the Announcements of Opportunity process. While peer review played no role in the selection of the Clementine and NEAR missions (see Chapter 4), COMPLEX believes that such competition should be an essential element of a successful Discovery program.

Maintenance of a schedule of reasonably frequent launches is essential to the viability of a small-missions program. Discovery missions are intended to address highly focused goals. Some may go to comets, others to the surfaces of the terrestrial planets or the Moon, others to asteroids, and yet others to probe atmospheres of the outer planets. Each mission will add incrementally to the science in a particular area. Instead of comprehensive data returns from large missions once a decade or less frequently, small but, it is hoped, more frequent inputs of data will be received from a spectrum of objects. One launch per year is highly desirable to maintain a reasonable data flow on a breadth of topics. Such a launch rate would permit a variety of science goals to be addressed as well as allow follow-up missions to a similar, or the same, object within a decade if warranted. One cometary mission might, for example, be followed several years later by a second mission designed to address questions raised by the first. The goals of the program could shift with time in response to the slow but steady stream of new information.

A launch rate of one per year also has programmatic implications. An essential property of the small-missions concept is that the time between initial selection and launch of an individual mission is short, between three and five years. Because this time is brief, the dollars spent by any single mission from one year to the next changes substantially. Thus, the maintenance of an approximately level overall funding profile requires frequent launches, and one launch per year is a reasonable goal. With launches every year, some missions would be ramping up as others were ramping down, but the funding level of the whole program would be roughly constant.

\section{RISK PHILOSOPHY}

Space exploration-especially, long flights to the planets-has always been a risky enterprise in which failures are expensive and embarrassing. As discussed above, the desire to minimize risk has led to substantial management overhead and, indeed, to a positive feedback loop relating increased cost with supposed risk reductions. After repeated iterations, the space program seems to have reached a situation where much of the manage- 
ment overhead creates only the illusion of risk reduction. COMPLEX notes that failures have not been absent from more expensive missions; rather than using additional funds to reduce risk, such programs merely carry more hardware and software, which are available to fail. It is essential, therefore, to break this vicious circle and to try a new approach. The recommendations returned to NASA by its advisory management groups with respect to the Discovery program reflect the need for such a change. The recent, largely successful, Clementine mission demonstrates that a different management approach (not unlike that of NASA itself in its early days) can be effective. But the Clementine mission, which failed before achieving one of its primary technological goals (autonomous, real-time tracking of a cold asteroid during a flyby many months after launch), also points out a potential risk in some low-cost enterprises. Clementine's tight schedule, stringent budget, and the unavailability of sufficient contingency funds shortly before launch each may have been indirect causes of the software error that ultimately led to the spacecraft's demise. ${ }^{2}$

It is essential to recognize, however, that failures will occur in the future, as they have in the past, and that the ability to deal with such disappointments must be integral to the new NASA philosophy. Taking a risk means being prepared to face a loss. (COMPLEX again notes that failures are not absent in more expensive missions.) First, a commitment to an adequate launch rate must be sustained, not allowing any single failure to jeopardize the whole program. Second, the ability to recover quickly from failure must be built into the program. Finally, the experience gained in failures must be used to estimate future risks reliably, as well as to learn how to decrease hazards; such a strategy is only justifiable if the flight rate is appreciable.

Facing risk during the development phase must also be considered, since one feature of a small-missions program should be that a mission may be canceled if the projected milestones and budget are not within their proposed envelopes. It should be kept in mind, nonetheless, that innovation could either increase or decrease risk for a particular mission, and this aspect will have to be judged on a case-by-case basis.

Other types of risk also need to be considered. A small mission, with a single scientific objective, may fail if that narrow objective is ill-conceived, or if its experiment is unsuccessful for reasons that could not be predicted in advance. Nonetheless, science may occasionally still benefit: for example, in the former case of an ill-conceived objective, an incorrect hypothesis may be eliminated (as with the null result obtained by the Michelson-Morley experiment); in the latter case, other unexpected results may sometimes be obtained (as with the Active Magnetospheric Particle Tracer Explorer (AMPTE), where chemical releases were not detected as planned but the charge composition of the magnetospheric plasma was determined). COMPLEX notes that, with missions of broader scope having multiple goals, it should be expected that at least some objectives will be satisfied unless a spacecraft failure occurs.

\section{INFRASTRUCTURE}

The extensive infrastructure required for large, complex missions is unnecessary for small missions. For a program of small missions, infrastructure should exist only because of mission requirements rather than by tradition or administrative edict. Cost-effectiveness should be sought through competition rather than through false hopes of obtaining economies of scale by requiring common equipment for all missions in the program. Specifically, a program of small missions should emphasize innovative ways to maximize science return for minimum cost without placing restrictions on (1) the launch vehicle, (2) the spacecraft bus, (3) the payload, (4) the data rate, (5) a specific management structure, or (6) a specific institution to run mission operations.

\section{SUPPORTING TECHNOLOGY}

The success of a small-missions program will depend in part on the availability of low-cost, small, capable science instruments. Such instruments cannot be developed within individual missions because of the time needed for a concept to mature. NASA's Planetary Instrument Definition and Development Program (PIDDP) is currently the only significant source of funds for development of new planetary science instruments. But this program is limited and has traditionally been able to support development of only a few instruments at a modest level. Because of the diverse goals of the proposed Discovery program, the range of instruments expected to fly is large. 
Moreover, the constraints on instrument mass and power are likely to be tight. The availability of previously classified, capable, lightweight sensors and spacecraft systems that Clementine carried was an important factor in keeping the cost of this mission reasonably low. Department of Defense technology is now more readily available for transfer to and exploitation by space scientists. ${ }^{3}$ Thus COMPLEX recommends that the PIDDP program be expanded and that a significant fraction of its resources be devoted to the development of instruments necessary to make the Discovery program a reality. An alternative would be to have within Discovery a precursor advanced technology development program, such as was the case with the Solar, Anomalous, and Magnetospheric Particle Explorer (SAMPEX) - the first of NASA's Small Explorers. Either approach would be consistent with the objective of supporting new technology.

COMPLEX does not recommend that parts of the existing Discovery budget be set aside for development of spacecraft components. Due to its limited resources, the Discovery program as currently conceived is an inappropriate source of funds for advanced spacecraft design. The role of NASA's Office of Space Access and Technology is to support advanced design, as it is doing with the Lewis and Clark Earth-observation satellites; this expertise should be brought to bear on the Discovery program's needs.

\section{SUBSIDIARY GOALS}

An important characteristic of a small-missions program is its focused science objectives. Adding other goals to the basic scientific mission will, of course, increase the cost. If other goals-such as education and new technology - are among the criteria used to judge a program, their costs, as listed in the proposal, should be separated from the basic scientific component so that review panels can understand clearly the expense of each component of the project. Ideally, separate funding sources should be identified to support any subsidiary goals.

One benefit of reducing the scale of missions is that they can involve smaller institutions such as universities. Incorporating a larger section of the community should, through competition, lead to reduced costs and will enhance opportunities for both new technologies and education.

\section{Technology}

While the complexity and expense of planetary missions have been growing, high-technology industries outside NASA have been creating new products with improved capabilities at lower cost. The most striking example is, of course, the computer industry. We have learned to expect that capabilities in that field will grow rapidly even as prices decline dramatically. Another advancing field is materials science, which creates the prospect of lighter yet more capable spacecraft. In space-mission design there have been striking examples of innovative technology, some of which were incorporated in Clementine, in part as a result of the Strategic Defense Initiative of the 1980s. Unfortunately, not all the advances in these and other fields have been put to use in civil space missions. ${ }^{4}$ The Lewis and Clark programs, initiated under the Small Spacecraft Technology Initiative program of NASA's Office of Space Access and Technology, is designed to accelerate this transfer of technology.

As with Lewis and Clark, Discovery missions are capped in cost and weight, and will, in many cases, benefit from new technology. But any substantial development of new technology within a particular mission would certainly increase the final price of that mission. Ideally, mission requirements and competition, not an administrative dictum, should be the judge of what, and how much, new technology should be incorporated into any mission. The new technology may enable richer scientific returns from the mission as well. New technology may also heighten the risk of failure, and insurance against this risk should be part of the mission plan. If the development of new technology is to be a significant aspect of the Discovery program, its role must be clearly and consistently stated. In other words, does the program seek to stimulate new technology? Or does the program wish to avoid new technology so as to keep unknowns to a minimum? 


\section{Education}

Small missions provide a variety of opportunities for education at K-12 levels. There are several examples of extensive educational outreach programs associated with, for example, the Hubble Space Telescope and less expensive activities such as the Extreme Ultraviolet Explorer and the Kuiper Airborne Observatory. Such missions, both large and small, employ educators with strong scientific backgrounds to coordinate activities with local Space Grant colleges, teachers' colleges, and local school teachers; these groups bring the space missions into the classroom, public libraries, and museums (via electronic media, audio-visual materials, interdisciplinary projects, and so on) as well as organize school visits to witness the development and construction of a spacecraft and the operation of a mission center (such as Clementine's "Batcave").

The involvement of universities in small missions is also an excellent chance to train scientists and engineers. The aim is not to produce more planetary scientists, but to use the opportunity to excite and inspire students in various disciplines at both undergraduate and graduate levels and to provide technical, scientific, and managerial experiences that might be extremely valuable for a wide variety of careers. The most desirable missions for student participation are those that are completed in at most a few years, so that a student can be a part of the entire mission-not just analyze data obtained a decade earlier. Examples of successful student involvement in small missions are provided by the Solar Mesosphere Explorer at the University of Colorado and the Extreme Ultraviolet Explorer at the University of California, Berkeley.

While the involvement of a motivated student work force may reduce mission costs, an effective educational outreach program will need additional funds. Such outreach programs might be funded through NASA's present education grants. In addition, it is important to include the costs of evaluating the effectiveness of educational programs. Nevertheless, it must be recognized that relatively few dollars could yield enormous benefits to the nation's educational system.

\section{INTERNATIONAL COOPERATION}

A program of small planetary missions could include participation in non-U.S. flights. Opportunities may arise to place instruments on, or otherwise participate in, international missions at costs comparable to, or less than, those of a typical Discovery mission. As a general rule, COMPLEX favors international participation and cooperation as a means of optimizing the scientific return of planetary missions against the resources being applied by individual countries. ${ }^{5} \mathrm{~A}$ full discussion of the complications and pitfalls inherent in major international collaborations raises issues far beyond the scope of this study and COMPLEX's competence to address. A simpler issue, and one that COMPLEX did discuss, is the use of Discovery funds for the provision of instruments of opportunity on foreign planetary missions. COMPLEX's guiding principle in such cases is that it is essential that such participation be competitive and consistent with the attributes of small missions listed above. For example, one essential property of Discovery missions is that they are to be implemented quickly, and yet international participation may require accommodation to the budget and planning cycles of partner nations, which may well be significantly longer than the planning cycles of typical Discovery missions.

Nonetheless, international programs, as illustrated by the plans for Japan's Planet-B mission, can sometimes satisfy COMPLEX's suggested guidelines. Planet-B is scheduled for launch in August 1998 and will enter orbit around Mars in October 1999. In addition to some dozen Japanese experiments, the spacecraft will carry a U.S. mass spectrometer designed to investigate the density profile and composition of the martian thermosphere and lower exosphere. Since the scope and development schedule of Planet-B are broadly consistent with the philosophy of the Discovery program, COMPLEX would have few reservations about having future opportunities, such as this one, openly compete for Discovery funds. NASA's planned involvement in the European Space Agency's Rosetta mission is a possible counterexample to Planet-B. This major mission, approved by ESA in late 1994 and scheduled for launch no sooner than 2003 , will rendezvous with, and deploy an experimental package on, the nucleus of a comet some years later. ${ }^{6}$ If successful, Rosetta will recover some, if not all, of the science lost with the cancellation of NASA's Comet Rendezvous/Asteroid Flyby (CRAF) mission. A mission of this type has been and remains of the highest priority to COMPLEX. ${ }^{7}$ However, COMPLEX is not in favor of a U.S. contribution to 
Rosetta (in the form of, for example, the surface science package) being funded as a Discovery mission. A commitment to participate in Rosetta now would tie up Discovery funds in a mission that would not be launched for almost a decade-a clear violation of the rapid-development aspect of the Discovery philosophy. On the other hand, deferring commitment to participate in Rosetta until closer to launch would, almost certainly, be unacceptable to ESA.

Although not discussed at length, one concern of COMPLEX is that potential uses of Discovery funds, including international cooperation, compete fairly against each other. Occasionally in the past, an international opportunity has arisen, and time has not permitted normal competitive processes to be followed to meet the opportunity. The same rationale applies to other potential applications of Discovery funds. The program should not be considered as a fund to support a miscellany of projects or external objectives, but rather should be used only to finance quick, low-cost flight opportunities judged in open competition. Another concern is that differences in national cultures, practices, and mechanisms by which missions are approved may lead to misunderstandings that could sour future relationships. A prime example is NASA's failure to formally participate in ESA's International Gamma-Ray Astrophysics Laboratory (INTEGRAL) mission.

\section{PROGRAM ISSUES}

\section{Mission Operations}

The wide variety of types of small planetary missions will lead to a range of ways of operating the missions. Some missions may require extensive use of the Deep Space Network and the infrastructure provided by NASA's Jet Propulsion Laboratory. Others will be able to operate an entirely independent ground station or have a small student-run operations center linked to the spacecraft via a NASA center. Moreover, a mission that involves monitoring a target from Earth-orbit over months or years will have very different operational requirements than a probe returning data at a high rate for a brief interval as it flies by an asteroid or descends through a planet's atmosphere. Thus, it is impossible for one mode of operation to suit all missions. PIs should be encouraged to find innovative ways to operate missions that optimize the science return for minimum cost. At the same time, COMPLEX recognizes that mission operations is the area where perhaps the greatest contributions can be made to the subsidiary goals of technology transfer and education with the least risk to mission success. One possibility, for example, would be to set up parallel data processing and archiving systems, each embodying a different philosophy and technical implementation. In such an approach, data from the mission would not only be downlinked to a conventional control center, but it would also be directed simultaneously via the Internet to mission scientists' workstations, to classrooms, and to moot control rooms staffed by student volunteers, or even to experimental artificial intelligence systems. Improvements in mission software or instrument control might have broader application than would more sophisticated spacecraft systems or instrumentation.

In the past, the cost of mission operations has been considered separately from the costs for mission development and construction. A program of small missions should view mission operations as part of the total mission costs. The past philosophy of costing a mission as "launch plus 30 days" has simply pushed the financial burden into a different part of NASA's budget. A further difficulty arises when a mission survives beyond its initial prime phase; a mechanism needs to be in place for deciding whether extended mission operations should be funded and what the source of those dollars should be. Rather than whittle away at the support scheduled for new Discovery missions, other sources, such as university consortia, should be sought if missions (e.g., Earth-orbital telescopes) are extended beyond their nominal lifetimes.

\section{Data Analysis and Archiving}

The initial products of planetary missions are the data. It is essential that these data be made available to the public and also archived in the Planetary Data System (PDS) in a timely manner. A plan that describes the data to be archived and the schedule for this activity should be included in the original proposal. Emerging information technologies make both these tasks relatively simple. For example, even today images or data displays (with 
descriptive text) can be made available through the Internet on the World Wide Web, accessed via an HTML browser such as Mosaic or Netscape, and optical disks have eliminated the need for vast storage rooms full of data tapes.

Nevertheless, proper analysis of the data will require the support of scientists either on the original mission team or as guest investigators. In the past, project management has tended to spend funds originally marked for data analysis on coping with cost overruns in design and construction phases earlier in the mission. The rigorous costing required for a successful program of small missions should ensure that sufficient funds remain available for data analysis by the science team. Funds for guest investigator programs and extended analysis programs will have to be made available from the Supporting Research and Technology program. Efforts need to be made early in the program to solicit guest investigators; this should bring young scientists aboard Discovery teams even when PIs are senior investigators.

\section{REFERENCES}

1. Nash, Doug (ed.), Discovery Program Workshop: Summary Report, San Juan Capistrano Research Institute, San Juan Capistrano, Calif., 1992.

2. Space Studies Board, National Research Council, Lessons Learned from the Clementine Mission, National Academy Press. Washington, D.C., in preparation.

3. Appelby, J. (ed.), Workshop on Advanced Technologies for Planetary Instruments, LPI Technical Report 93-02, Parts 1 and 2, Lunar and Planetary Institute, Houston, Tex., 1993.

4. See, for example. Aeronautics and Space Engineering Board, National Research Council, Technology for Small Spacecraft, National Academy Press, Washington, D.C., 1994.

5. Space Studies Board, National Research Council, An Integrated Strategy for the Planetary Sciences: 1995-2010, National Academy of Sciences, Washington, D.C., 1994, pages 32-33.

6. Joint ESANASA Science Definition Team, ROSETTA: The Comet-Nucleus Sample Return, ESA SP-1125, ESA Publications Division, Noordwijk, The Netherlands, June, 1991.

7. Space Studies Board, National Research Council, An Integrated Strategy for the Planetary Sciences: 1995-2010, National Academy of Sciences, Washington, D.C., 1994, page 189. 


\section{Management Structure and Procedures}

Given anticipated strict development and budget constraints, successful implementation of small-planetaryexploration missions will pose significant management challenges. These challenges will require the coordination of all of the involved parties and the adoption of a new culture within the planetary science and technology communities. NASA has appreciated the need for such change for some time and has, within the context of its current Discovery program, undertaken a series of reviews of the necessary management changes. These reviews have produced two sets of recommendations, The Final Report on the Discovery Management Workshop ${ }^{1}$ and Report of the Discovery Program Cost and Management Team, ${ }^{2}$ that COMPLEX believes to be useful and informative. Aspects of these reports have been expanded to the wider context of small missions (e.g., Mars Surveyor) and are incorporated within the summary discussions presented below.

\section{SELECTION CRITERIA AND PROCEDURES}

The most important aspect of the selection process for small missions is that, after open solicitation of proposals, missions be chosen on the basis of peer review. The competitive nature of this process is designed to bring forth the best scientific, technical, and management approaches and to foster creative solutions for achieving mission success in a fiscally constrained environment. It is essential that the criteria be clearly outlined in the Announcement of Opportunity for each mission, that the selection process strictly follow these guidelines, and that the process be allowed to develop without undue influence from outside pressures. Fair and open competition will maximize the chances of programmatic success and will maintain the support of the scientific community. It is assumed that the selection criteria for small missions will place roughly equal weight on the scientific considerations and management approach, following the example developed already for NASA's current Discovery program.

The long-term health of a small-missions program is tied closely to the control of mission costs. Therefore, strong weight in the selection process should be given to the development and demonstration of realistic costs for these missions. Building on the recommendations in the Discovery Management Workshop final report, COMPLEX believes that (1) the use of new technologies to meet the goals of small missions is desirable; (2) technology should be a consideration in mission selection, but the introduction of new technology must be driven by mission objectives; (3) the risk of new technology must be understood and a backup plan developed in case the price of this technology causes or leads to exceeding the cost ceiling of the mission; and (4) support from the Planetary 
Instrument Definition and Development Program and NASA's Office of Space Access and Technology should be considered for the development of new technology so that the missions can focus on the application of these technologies.

However, small missions should not become vehicles simply to demonstrate technical capabilities and achieve political, rather than scientific, success. In other words, small missions should not be driven primarily by requirements to demonstrate technology, as Clementine was; to be testbeds for future missions, as Mars Pathfinder is; or by the need for a source of funding to make a NASA contribution to an international program such as ESA's Rosetta. Science objectives must continue to receive the highest priority in the mission selection process.

\section{MANAGEMENT PRACTICES: APPROACH, COST CONTROL, AND ROLES}

Small, low-cost missions provide an excellent opportunity to develop innovative means to manage the technical development of planetary missions. COMPLEX assumes that missions will be proposed and run by a Principal Investigator (PI) who will be fully responsible and accountable for mission success. The PI should have the authority to make decisions on trade-offs related to science performance, mission risk, mission design, and other matters as well as to ensure that the mission remains within the basic scope originally proposed. COMPLEX accepts the position that, since the PI's reputation and future are on the line, that individual will attempt to do all that is required to assure mission success.

A major strength of the small-mission scheme is to encourage innovative approaches to streamline management. Thus, the management structure of the mission team, the role of the PI relative to the industrial and NASA partners, and the methods and incentives for cost control should be chosen by the PI. The relative roles and responsibilities of these components, as well as of the PI vis-à-vis the project manager, must be clearly defined at the outset. The competitive review process will provide the primary means by which different approaches are evaluated; if the review process works properly, the most effective method should be selected.

A new NASA management culture is essential to assure the long-term success of any program of small planetary missions. In particular, the interface between the mission-team and NASA management must be streamlined:

- An excessively intricate management interface is inconsistent with the program's stated goals of reduced cost and complexity.

- NASA should develop an integrated team approach in its relationships with the project in order to maximize the exchange of information that is useful to technical development, program management, and cost control.

- All requirements and deliverables must be clearly identified and agreed to by all parties prior to the initiation of the execution phases (i.e., phases $C$ and D) of a project and must remain fixed throughout the project's life.

- There must not be any hidden constraints or changes in external objectives and requirements during the mission development.

- It is essential that the funding profile be agreed to prior to project start and that the monies be provided reliably.

- The procurement process traditionally used by NASA may need to be modified in order to meet the demands of rapid deployment and cost control, as it was for the recent Lewis and Clark program of small Earth observation satellites. One area that needs to be studied is the possible relaxation of onerous auditing requirements that small PI-led teams may be ill-equipped to handle; obviously, any easing of these requirements must be accomplished with no lessening of fiscal responsibility. Other areas include the judicious use of single-source contractors to eliminate complex bid evaluations, and an emphasis on fixed-price contracts and performance-based fees to minimize cost overruns.

\section{REVIEW AND OVERSIGHT}

An important goal of small missions is to achieve science objectives while reducing management cost and complexity. Reaching this goal, however, requires that other aspects of mission management, including review 
and oversight, be streamlined to a level consistent with the management approach developed within each project. Periodic reviews are a necessary part of any successful enterprise and will naturally be required by the PI to maintain internal oversight of the project. External oversight should be carried out via NASA's participation in the internal review process; the emphasis should be technical exchange of information, rather than dictation of additional reviews.

Increased external oversight does not necessarily correlate directly with a higher probability of mission success through decreased risk and decreased cost. As discussed in Chapter 3, a comprehensive risk philosophy must be developed that incorporates a realistic assessment of any benefits of added oversight. NASA must be willing to accept a share of the risk associated with low-cost missions as well as to acknowledge that extensive review and oversight are neither affordable nor consistent with the small-mission philosophy. COMPLEX recommends that each project propose an "oversight ceiling," consistent with the management approach, which can serve as a baseline for developing a review plan.

\section{DESCOPING AND/OR CANCELLATION}

The development of the small-mission concept has been driven in large part by an attempt to reduce mission costs and thereby increase the number of mission opportunities. Thus, the community clearly recognizes the necessity for discipline in controlling and containing costs in order to assure the long-term success of smallmission programs. Options for descoping are required within the evaluation process for Discovery missions and are recommended for all missions with limited budgets, schedules, and science objectives. The establishment of a "science floor" may be appropriate for low-cost mission proposals but, if introduced in good faith by a PI, should not be used by NASA to vitiate mission capabilities. It is assumed that each team will have a detailed descoping plan in place in the event of unanticipated problems leading to cost growth.

External changes beyond the control of individual mission teams can lead to significant cost growth. Once the PI and NASA agree to various aspects of mission design such as launch date, launch vehicle, performance requirements, and the acceptable level of risk, NASA must fulfill its commitments. Not only the total amount of funding, but also the funding profile must be maintained. Any cost growth associated with external changes or deviations from the funding schedule should be accurately determined and distinguished from any internal cost growth that occurs within a mission.

If a mission is projected to overrun its allocation even after implementation of responsible options for descoping, or to fall below its science floor, then it should be reviewed for possible termination. The criteria for implementation of this extreme measure should be clearly understood by both NASA and the mission team at the initiation of a project. NASA and the PI should accept that cancellation can occur at any point within the development process but, obviously, saves less money if it occurs too late in phase D. A detailed project plan should be developed at the program's initiation, with technical milestones against which potential cost increases can be identified and evaluated early in the program. It is critical that the PI devise and document a mechanism for internal project identification of potential problems and have the means and a plan by which descoping actions can be taken. Prudent management of any space mission also requires that reserve funds be put aside to cover unexpected problems. This is especially true for small, deep-space missions with tight schedules, such as Discovery.

\section{REFERENCES}

1. National Aeronautics and Space Administration, The Final Report on the Discovery Management Workshop, report of a workshop held at the San Juan Capistrano Research Institute, April 13-15, 1993; submitted by the Executive Committee (Frank Carr, W.E. Giberson, J.S. Martin) on May 25, 1993.

2. National Aeronautics and Space Administration, Report of the Discovery Program Cost and Management Team to Dr. Wesley $\mathrm{T}$. Huntress, Jr., July 10, 1991. 


\section{Recommendations}

Many diverse objects across the solar system must be studied to achieve the broad goals of planetary and lunar exploration, as outlined in COMPLEX's report, An Integrated Strategy for the Planetary Sciences: 1995-2010. ${ }^{1}$ An effective program for planetary and lunar exploration also dictates a mix of mission sizes, ranging from comprehensive missions with multiple objectives, such as Galileo and Cassini, down to relatively low cost missions, such as those in the Discovery program. In a program of small missions, various ones might be designed to enhance or augment comprehensive studies of particularly interesting objects (e.g., Mars and Jupiter), carry exploration further toward answering specific science questions (e.g., Moon, Mercury, or Venus), perform reconnaissance of classes of objects that have received relatively little attention to date (e.g., comets and asteroids), investigate planetary phenomena from Earth orbit, or exploit targets of opportunity.

For small missions to fulfill their promise, it is essential that the overall program contain certain elements. In particular, COMPLEX believes that the following criteria should be satisfied:

1. A continuing budget line should be initiated that is dedicated to small planetary missions that focus on specific, well-defined objectives and are capable of yielding significant scientific results. A series of missions is required to address the broad range of top-priority questions in an effective way. Technical, programmatic, infrastructure, and educational interests are best served by a continuing sequence of missions. The choice of missions should be responsive to the scientific rationale and address key questions and objectives outlined in COMPLEX's Integrated Strategy.

2. The Discovery program should be funded at a level that will permit the launch of at least one mission per year, with approximately half of the accepted missions supported at a level close to the currently announced budget cap of $\$ 150$ million (FY 1992 dollars), not including inflation. This level will allow the Discovery program to fulfill its major role of providing frequent, rapid access to space while carrying out a broad range of high-quality science.

3. Each mission in the program should be proposed as an integrated package led by a principal investigator (PI), and the missions should always be selected through open competition. The PI should have full authority to decide the appropriate balance among science performance, mission design, and acceptable risk so as to ensure that the investigation achieves the greatest science return while remaining within the originally proposed cost and schedule.

4. NASA should not impose arbitrary constraints (e.g., preselection of launch vehicle, spacecraft bus, pay- 
load, data rate, target locale, or management structure) on mission design. Fewer restrictions will permit the most creative and cost-effective solutions for the broadest range of possible mission and target types.

5. The budget, schedule, and risk envelope must be identified in the conceptual and definition phase of mission planning, because success at any price is not acceptable in a cost-constrained mission. Candidate PIs must outline and justify their approach to the assessment and management of risk in the initial proposal, and NASA management must be willing to accept a share of the risk. It is essential for NASA to adhere to the agreed-upon funding profile once the agency has made a commitment for mission development and launch.

6. Past NASA practices must change in order to foster the development of a streamlined approach to management of each complete mission. This approach must minimize the level of NASA oversight by eliminating unnecessary reviews and reducing day-to-day interactions with, and direction to, each team; it must also reduce changes in the external requirements to the maximum extent possible. NASA's procurement process may need to be modified if small PI-led teams are to achieve the rapid development of missions in a cost-constrained environment. Areas that should be investigated include the relaxation of complex auditing and bid evaluation procedures, and the increased use of fixed-price contracts and performance-based fees.

7. As soon as they have been calibrated and validated, data should be archived expeditiously. Data and all subsidiary information (e.g., spacecraft ephemerides) needed for their interpretation should be deposited in NASA's Planetary Data System (PDS) to ensure their prompt availability to the larger community. Some preliminary analysis of these data is the responsibility of the science team. Later analysis of these data, to derive scientific information or knowledge, should be funded separately.

8. NASA's Planetary Instrument Definition and Development Program (PIDDP) should be augmented to infuse new technologies into lightweight science instruments that are likely to be valuable for small missions. Instrument development costs can be substantial and thus would be difficult to carry within individual, costconstrained missions. A vigorous development program closely tied to specific mission plans is necessary to assure that highly capable instruments will be available to support future missions.

9. The option of using elements of the small-mission philosophy for Mars Surveyor and future large missions should be studied.

\section{REFERENCE}

1. Space Studies Board, National Research Council, An Integrated Strategy for the Planetary Sciences: 1995-2010, National Academy of Sciences, Washington, D.C., 1994. 


\section{APPENDIX}

\section{Missions Mentioned in This Report}

Active Magnetospheric Particle Tracer Explorer (AMPTE)

A U.S.-German-U.K. program that used three satellites to conduct active experiments in the solar wind and determine the sources of magnetospheric particles. All three spacecraft were launched in August 1984.

\section{Artemis}

A series of small, low-cost, robotic lunar landers designed, as a part of the Bush Administration's Space Exploration Initiative, to conduct research enabling the return of astronauts to the Moon. See Lunar Scout

\section{Cassini}

A very large Saturn orbiter scheduled for launch in October 1997. Upon arrival at Saturn in 2004, it will deploy the European Space Agency's Huygens Titan atmospheric probe and will conduct complex, multidisciplinary observations of the planet's atmosphere, rings, magnetosphere, and satellites. See Huygens.

\section{Challenger}

The space shuttle destroyed during launch in January 1986.

\section{Clark}

One of a pair of small, low-cost Earth observation satellites scheduled for launch in 1996. See Lewis.

\section{Clementine}

A technology demonstration mission launched by the Department of Defense's Ballistic Missile Defense Organization in January 1994. The mission mapped the entire Moon but failed before flying by asteroid 1620 Geographos.

Comet Rendezvous/Asteroid Flyby (CRAF)

A proposed 8-year mission designed to rendezvous with a comet and accompany it for many months, and to make a close-up flyby of one or more asteroids. Difficulties encountered during the preparation of the FY 1993 budget forced NASA to cancel CRAF. 
Cosmic Microwave Background Explorer (COBE)

A NASA science mission, launched in November 1989 and operational until December 1993, that addressed basic questions about the temperature, spectrum, and isotropy of the cosmic background radiation.

Discovery

A line of small planetary missions characterized by a 3-year development schedule and a budget cap of $\$ 150$ million (FY 1992). Mars Pathfinder and Near-Earth Asteroid Rendezvous (NEAR), the first two Discovery missions, were granted new starts in NASA's FY 1994 budget.

\section{Earth Probes}

A proposed line of small, low-cost Earth observation satellites. See TOMS, TRMM.

Explorer

A continuing line of moderate-cost astrophysics/space physics missions that includes the Infrared Astronomical Satellite, the Extreme Ultraviolet Explorer, the International Ultraviolet Explorer, and the Cosmic Microwave Background Explorer.

\section{Extreme Ultraviolet Explorer (EUVE)}

A NASA astrophysics mission, launched in June 1992 into a near-Earth orbit to survey the sky in the 100- to 912-angstrom spectral region.

\section{Galileo}

A very large Jupiter orbiter, launched aboard the space shuttle Atlantis in October 1989. When it reaches Jupiter in December 1995, it will deploy an atmospheric entry probe and then conduct complex, multidisciplinary observations of the planet's atmosphere, rings, magnetosphere, and satellites.

\section{Giotto}

The European Space Agency launched this spacecraft in July 1985 on a trajectory that enabled it to perform a fast flyby of the nucleus of Halley's comet in March 1986. Although severely damaged during the encounter, the spacecraft was later reactivated and performed a close flyby of the nucleus of comet Grigg-Skjellerup in July 1992.

\section{Hubble Space Telescope}

A NASA-ESA 2.4-meter optical-ultraviolet telescope placed in low-Earth orbit by the space shuttle in April 1990. Although the telescope's primary mirror was later discovered to suffer from spherical aberration, its performance was restored by astronauts during a December 1993 servicing mission.

Huygens

The European Space Agency's contribution to Cassini, scheduled for launch in October 1997. The Huygens probe will conduct in situ observations of Titan's atmosphere and surface.

Infrared Astronomical Satellite (IRAS)

A cooperative astrophysics project involving NASA, the Netherlands, and the United Kingdom. Following its launch in January 1983, this cryogenically cooled telescope conducted a multicolor, all-sky survey at infrared wavelengths.

International Gamma-Ray Astrophysics Laboratory (INTEGRAL)

The large astrophysics mission scheduled for launch in 2001 by the European Space Agency. Budgetary problems prevented NASA's full participation in this mission as originally planned. 
International Ultraviolet Explorer (IUE)

This NASA-ESA-U.K. mission was launched into a geosynchronous orbit above the Atlantic in January 1978. From this vantage point, this $40-\mathrm{cm}$ telescope conducts around-the-clock spectroscopic observations of ultraviolet sources.

\section{Interplanetary Monitoring Platform (IMP)}

A series of missions designed to study Earth's magnetosphere and interplanetary space. The last, IMP-8, was launched in 1972.

\section{Kuiper Airborne Observatory}

A C-141 transport equipped with a $90-\mathrm{cm}$ telescope, capable of performing observations in the infrared and submillimeter spectral regions from altitudes in excess of 12,000 meters.

\section{Lewis}

One of a pair of small, low-cost Earth observation satellites. See Clark.

\section{Luna}

A series of 24 Soviet lunar missions, beginning with a lunar flyby, launched in 1959 and concluding with a sample-return mission launched in 1976.

\section{Lunar Observer}

A proposed Planetary Observer that would have been assembled from spare components from Mars Observer. Originally designed to provide purely scientific information about the mineralogy and geochemistry of the lunar surface, the mission plan was later modified to include collection of data that would enable future human exploration missions.

\section{Lunar Orbiter}

A successful series of five lunar missions launched in 1966 and 1967 . They were designed to support the Apollo program by completing a photographic survey of the Moon.

\section{Lunar Polar Orbiter}

A proposed robotic mission to conduct sophisticated remote-sensing observations of the Moon's surface to extend the measurements made by the Apollo missions.

\section{Lunar Scout}

The series of small lunar missions proposed in 1990 as part of the Space Exploration Initiative. Lunar Scout I and II would have used low-cost instruments to map the Moon in support of future human exploration missions. See Artemis.

\section{Magellan}

The first shuttle-launched interplanetary spacecraft. Following its launch from Atlantis in 1989, Magellan mapped almost all of Venus's surface using synthetic aperture radar and conducted measurements of the planet's gravitational field.

\section{Mariner}

A series of 10 NASA planetary missions that conducted observations of Venus, Mars, and Mercury in the period from 1962 to 1975 .

\section{Mars Geoscience/Climatology Orbiter}

Original name of Mars Observer. 


\section{Mars Observer}

The first and last of NASA's Planetary Observer series. It was launched in 1992 and was lost shortly before entering orbit around Mars in 1993.

\section{Mars Pathfinder}

Formerly known as the Mars Environmental Survey (MESUR) Pathfinder, this satellite is one of the first two Discovery missions and is scheduled for launch in December 1996. The mission will consist of a lander and a surface rover.

\section{Mars Surveyor}

A series of NASA Mars exploration missions, beginning with the Mars Global Surveyor, scheduled for launch in November 1996. The Global Surveyor will capture martian data using five spare instruments from the Mars Observer program. The missions will continue with a subsequent series of two small missions launched every 2 years, beginning with an orbiter and a lander to be launched in 1998.

\section{Near-Earth Asteroid Rendezvous (NEAR)}

One of the first two Discovery missions, the spacecraft is scheduled for launch in February 1996. In late December 1998, NEAR will rendezvous with the near-Earth asteroid 433 Eros and will study the asteroid for approximately 1 year.

\section{Pioneer}

A series of 13 NASA interplanetary spacecraft launched between October 1958 and August 1978. The series began with Pioneer 1, a failed lunar orbiter, and ended with Pioneer 13 (Venus), which conducted a multiprobe study of Venus's atmosphere. Pioneers 10 and 11 made the first flybys of Jupiter (December 1973) and Saturn (September 1979), respectively.

\section{Pioneer Venus}

Pioneer Venus 1 and 2, also known as Pioneer 12 and 13, conducted extensive observations of Venus using remote-sensing techniques and atmospheric probes, respectively. Both were developed from the Planetary Explorer concept and were launched in 1978. See Planetary Explorer.

\section{Planetary Explorer}

A proposed line of low-cost planetary missions using a common spacecraft bus. This program evolved into Pioneer Venus. See Pioneer Venus.

\section{Planetary Observer}

A proposed line of low-cost planetary missions using a bus based on a production-line Earth-orbiting spacecraft. The only mission to fly was Mars Observer. See Mars Observer.

\section{Planet-B}

The Japan-NASA joint mission using a spacecraft being developed by Japan's Institute for Space and Astronautical Science (ISAS) and scheduled for launch in August 1998. This mission, scheduled for arrival in October 1999, will investigate the neutral atmosphere of Mars for 2 years.

\section{Ranger}

A series of nine U.S. lunar hard landers, launched between August 1961 and March 1965. Rangers 7 through 9 successfully obtained television imagery of the lunar surface. 
Rosetta

An approved European Space Agency mission, scheduled to rendezvous with a comet in the latter part of the next decade. NASA participation in this major mission centers on provision of a surface-science package.

Small Explorer Program (SMEX)

A continuing series of highly focused and relatively inexpensive astrophysics and space physics missions. Each spacecraft weighs approximately 500 pounds and is expected to cost approximately $\$ 50$ million for design, development, and operations through the first 30 days in orbit. See SAMPEX and SWAS.

Solar, Anomalous, and Magnetospheric Particle Explorer (SAMPEX)

This mission, the first Small Explorer, was launched in July 1992. The mission has been successfully investigating the composition of local interstellar matter and solar material, as well as the transport of magnetosopheric charged particles into Earth's atmosphere.

\section{Solar Mesosphere Explorer}

This spacecraft was launched in September 1981 to study the photochemical and transport processes associated with ozone concentrations in the upper atmosphere. The mission operations center at the University of Colorado made extensive use of student labor.

Submillimeter Wave Astronomy Satellite (SWAS)

A Small Explorer mission designed to study interstellar molecular clouds by observing their emissions at submillimeter wavelengths. Scheduled for launch in 1995. See Small Explorer.

Surveyor

NASA's series of six robotic lunar landers designed to gather data in support of Apollo, launched between May 1966 and November 1967.

Total Ozone Mapping Spectrometer (TOMS)

A NASA instrument launched aboard Russia's Meteor-3 in August 1991 to make global measurements of atmospheric ozone. A free-flying version of this instrument will be one of the first of NASA's Earth Probes. See Earth Probes.

Tropical Rainfall Measuring Mission (TRMM)

A joint NASA-Japanese mission designed to measure global tropical rainfall, scheduled for launch in August 1997. It will be one of the first of NASA's Earth Probes. See Earth Probes.

Vega

A pair of Soviet spacecraft that conducted observations of Venus (1985) and Halley's comet (1986).

Viking

A pair of landers and orbiters that conducted extensive observations of Mars, including a search for life.

Voyager

A pair of spacecraft launched in August and September, 1977, designed to conduct reconnaissance observations of Jupiter (1979) and Saturn (1980 and 1981). Voyager 2 also conducted flybys of both Uranus (1986) and Neptune (1989). 
